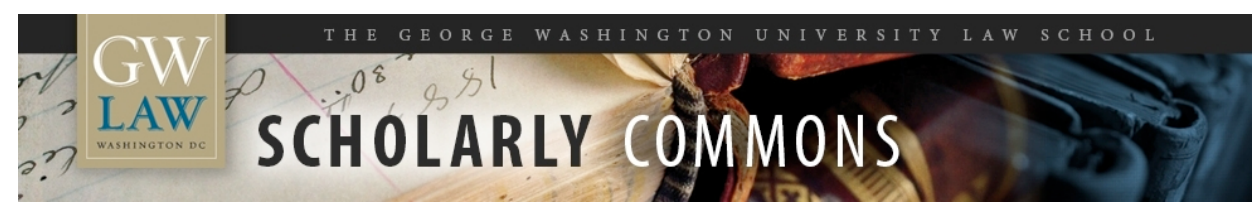

GW Law Faculty Publications \& Other Works

Faculty Scholarship

2010

\title{
Cultural Cognition of Scientific Consensus
}

Donald Braman

George Washington University Law School, dbraman@law.gwu.edu

Dan M. Kahan

Hank Jenkins-Smith

Follow this and additional works at: https://scholarship.law.gwu.edu/faculty_publications

Part of the Law Commons

\section{Recommended Citation}

Donald Braman et. al., Cultural Cognition of Scientific Consensus, 14 J. of Risk Research 147 (2010).

This Article is brought to you for free and open access by the Faculty Scholarship at Scholarly Commons. It has been accepted for inclusion in GW Law Faculty Publications \& Other Works by an authorized administrator of Scholarly Commons. For more information, please contact spagel@law.gwu.edu. 


\section{Cultural Cognition of Scientific Consensus}

Journal of Risk Research, in press

advance on-line publication at doi: 10.1080/13669877.2010.511246

Dan Kahan

Yale Law School
Hank Jenkins-Smith

University of Oklahoma

Donald Braman

George Washington Law School

Authors' Note. Research for this paper was funded by the National Science Foundation, Grant SES

0621840; by the Oscar M. Ruebhausen Fund at Yale Law School; and by the Center for Applied Social

Research at the University of Oklahoma. We gratefully acknowledge comments on an earlier draft by Jay

Koehler, Lisa Larrimore Ouellette, Mark Peffley, Jeffrey Rachlinski, Mike Spagat, and Maggie Wittlin.

Correspondence concerning this article should be addressed to Dan M. Kahan, Yale Law School, PO Box

208215, New Haven, CT 06520. Email: dan.kahan@yale.edu. 


\begin{abstract}
Why do members of the public disagree — sharply and persistently — about facts on which expert scientists largely agree? We designed a study to test a distinctive explanation: the cultural cognition of scientific consensus. The "cultural cognition of risk" refers to the tendency of individuals to form risk perceptions that are congenial to their values. The study presents both correlational and experimental evidence confirming that cultural cognition shapes individuals' beliefs about the existence of scientific consensus, and the process by which they form such beliefs, relating to climate change, the disposal of nuclear wastes, and the effect of permitting concealed possession of handguns. The implications of this dynamic for science communication and public policy-making are discussed.
\end{abstract}




\section{Introduction}

Despite the steady and massive accumulation of scientific evidence, the American public is as divided about climate change today as it was ten years ago (Pew Research Center 2009; Newport 2008). Nor is this the only issue on which the emergence of consensus, or near consensus, among scientists has failed to achieve anything close to that among members of the public: the safety of nuclear power (Slovic, Flynn \& Layman 1991; Barke \& Jenkins-Smith 1993); the toxicity of arsenic, radon and other groundwater chemicals (Sunstein 2005); the health consequences of vaccinating school girls against the human papillomavirus (Kahan, Braman, Cohen, Gastil \& Slovic in press) - all have featured intense political contestation over empirical issues on which technical experts largely agree.

Not all policy disputes turn on issues amenable to scientific investigation, of course, so no one would or should expect that what scientists have to say will resolve every conflict. But when empirical assessments of risk and risk abatement are exactly what members of the public are fighting about, why is the prevailing opinion of scientists - on questions only they are equipped to answer — so infrequently treated as decisive?

Myriad theories have been advanced for the limited influence of science in formulating the factual basis for public policy debates, but none seems complete. If the answer were that members of the public are simply less informed than experts (Iriwn \& Wynne 1996), one would expect disagreement on issues like climate change to abate in the face of widespread dissemination of scientific findings. Trust in experts varies across groups, and laypersons often evaluate information about risks and benefits with criteria that differ from those used by scientists (Slovic 2000; Jenkins-Smith 2001). Yet public debates rarely feature open resistance to science; the parties to such disputes are much more likely to advance diametrically opposed claims about what the scientific evidence really shows. The problem, it seems, is not that members of the public are unexposed or indifferent to what scientists say, but rather that they disagree about what scientists are telling them.

We present evidence in support of a novel explanation for the limited policy-shaping power of scientific opinion: the cultural cognition of expert consensus. The cultural cognition of risk is a theory 
that helps to explain public disagreement about the significance of empirical evidence generally (Kahan, Slovic, Braman \& Gastil 2006). The theory posits a collection of psychological mechanisms that dispose individuals selectively to credit or dismiss evidence of risk in patterns that fit values they share with others. We designed a study, including both correlational and experimental elements, to test the hypothesis that mechanisms of cultural cognition extend to evidence of what scientific expert opinion is on climate change and other risks.

\section{Theoretical Background and Conjectures}

\subsection{Cultural Cognition}

Cultural cognition refers to the tendency of individuals to fit their perceptions of risk and related factual beliefs to their shared moral evaluations of putatively dangerous activities. The cultural cognition thesis asserts that individuals are psychologically disposed to believe that behavior they (and their peers) find honorable is socially beneficial, and behavior they find base socially detrimental (Kahan, Braman, Monahan, Callahan \& Peters 2010).

Cultural cognition is the descendent of two other theories. The first is the cultural theory of risk associated with the work of Mary Douglas and Aaron Wildavsky (1982). The cultural theory of risk posits that individuals can be expected to form risk perceptions that reflect and reinforce one or another idealized "way of life." Persons whose values are relatively hierarchical and individualistic will thus be skeptical of environmental risks, the widespread acceptance of which would justify restricting commerce and industry, activities that people with these values prize; persons with more egalitarian and communitarian values, in contrast, resent commerce and industry as forms of noxious self-seeking productive of unjust disparity, and thus readily accept that such activities are dangerous and worthy of regulation. (Dake, 1991; Wildavsky \& Dake, 1990; Rayner 1992; Adams 1995). The second theory is the "psychometric paradigm." This position identifies recurring cognitive and affective dynamics that cause individuals to form risk perceptions systematically different from ones we might expect if such individuals were behaving consistently with rational decision theory (Slovic 2000). 
Cultural cognition attempts to fuse the cultural theory of risk and the psychometric paradigm in ways that permit each to answer questions posed by but not satisfactorily addressed by the other. The psychometric paradigm thus furnishes an account of the individual-level mechanisms through which cultural values shape risk perceptions: the opposing outlooks characteristic of hierarchy and egalitarianism, individualism and communitarianism, imbue putatively dangerous activities with resonances (positive and negative) reflected in affective appraisals of risk (Jenkins-Smith 2001; Peters, Burraston, \& Mertz 2004); invest instances of harm (or adverted harm) with significance, making them worthy of note and amenable to recollection in the way that the availability heuristic presupposes (Kahan \& Braman 2003); trigger the analogical associations that result in biased assimilation of information (Kahan, Braman, Gastil, Cohen \& Slovic 2009; Lord, Ross \& Lepper 1979); underwrite the social affinities that make others credible and trustworthy sources of risk information (Earle \& Cvetkovich 1995; Kahan, Braman, Cohen, Gastil \& Slovic in press); and create identity-protective motivations to conform one's beliefs to those of likeminded others in order to avoid dissonance and protect social standing (Kahan, Braman, Gastil, Slovic \& Mertz 2007; Cohen 2003). ${ }^{1}$ For its part, cultural theory remedies the psychometric paradigm with a much-needed theory of individual differences: the interaction of values with the psychological mechanisms featured in the psychometric position explain how one and the same dynamic - whether affect, availability, biased assimilation, source credibility, or others - can nevertheless produce diametrically opposed risk perceptions in different people and indeed intense forms of polarization across groups of persons. By experimental and other empirical modes of investigation, such processes have been shown to generate differences in perception of myriad putative sources of risk, from nuclear power to guns (Kahan, Braman, Gastil, Slovic \& Mertz 2007), from nanotechnology to vaccination of school girls for HPV (Kahan, Braman, Slovic, Gastil \& Cohen 2009; Kahan, Braman, Cohen, Gastil \& Slovic in press).

\footnotetext{
${ }^{1}$ The proponents of the cultural theory of risk have (boldly and skillfully) presented a functionalist account of the means by which culture, as they conceive it, affects the formation of risk perceptions (Thompson, Ellis \& Wildavsky 1990; Douglas 1986), a feature of the theory that others have criticized (Boholm 2003). Cultural cognition, in contrast, posits that culture is connected to perceptions of risk and other facts that individuals understand to bear on
} 


\subsection{Perceptions of expert consensus}

Of course, laypeople are not in a position either to investigate for themselves or fully to understand the technical data compiled by scientific researchers on risks of these sorts. They must therefore turn for assistance to experts. One might thus anticipate (or at least hope) that regardless of the tendency of predispositions and biased information processing to push people of opposing cultural outlooks apart, the need of all them for expert guidance would cause them to gravitate toward the consensus positions among scientists.

The difficulty for this suggestion, however, is that it assumes individuals of diverse outlooks will by and large agree on what scientific consensus is. The process by which individuals form beliefs about expert opinion might itself be subject to the dynamics of cultural cognition. If so, individuals' perceptions of scientific consensus will come to fit their cultural predispositions toward risk generally.

Cultural cognition might be expected to shape beliefs about expert consensus through the interaction of values and the "availability heuristic" (Kahneman \& Tversky 1982). Imagine that when individuals consider an issue like climate change they perform what amounts to a mental survey of experts they have observed offering an opinion on this issue. The impact "scientific consensus" will have on their thinking will thus turn on how readily they can recall instances of experts taking positions one way or the other. The cultural cognition thesis predicts that individuals will more readily recall instances of experts taking the position that is consistent with their cultural predisposition than ones taking positions inconsistent with it.

A cultural availability effect of this sort could result from the influence of other mechanisms of cultural cognition. To start, cultural cognition influences perceptions of credibility. Individuals more readily impute expert knowledge and trustworthiness to information sources whom they perceive as sharing their worldviews and deny the same to those whose worldviews they perceive as different from theirs (Siegrist, Cvetkovic \& Roth 2000; Earle \& Cvetkovich 1995; Kahan, Braman, Cohen, Gastil \& Slovic in

their welfare through discrete psychological processes, operating at the individual level (Kahan, Braman, Cohen, 
press). As a result, information sources who share their worldviews will be overrepresented in individuals' mental inventories of experts. If individuals observe that a view they are predisposed to believe is in fact espoused by a disproportionate share of the information sources whom individuals recognize to be "experts" by virtue of such a cultural affinity — as could happen if these putative experts are also subject to forces of cultural cognition - individuals of opposing outlooks will end up with different impressions of what "most" credible experts believe.

Even if there is no discernable correlation between experts' positions and those experts' perceived values, however, other mechanisms might cause individuals of opposing worldviews to form opposingly skewed mental inventories of expert opinion. For example, individuals tend to search out information congenial to their cultural predispositions (Kahan, Braman, Gastil, Cohen \& Slovic 2009; SchulzHardt, Frey \& Lithgens 2000). Accordingly, we might expect individuals to work harder to find expert opinion supportive of their existing, culturally informed perceptions of risk than they do to find expert opinion that challenges those perceptions.

Finally, even if biased searching is removed from the equation, biased assimilation could generate culturally valenced availability effects on perceptions of expert views. Confronted with a purported expert source, individuals must decide whether that source really does possess expertise before they can determine whether and how to update their mental inventory of expert positions. The same tendency individuals have to attend to information in a biased way that reinforces their priors could lead them to form biased assessments of the authority and knowledge of putative experts in a manner that fits their predispositions. This process, too, would lead individuals of opposing outlooks to arrive at radically different results when they conjure examples of "expert opinion" on particular issues.

On this account, then, what most scientists believe is simply another empirical fact no different from any other that bears on a disputed question of risk. As such, scientific consensus cannot be expected to counteract the polarizing effects of cultural cognition because apprehension of it will necessarily occur

Gastil \& Slovic in press; DiMaggio 1997). 
through the same social psychological mechanisms that shape individuals' perceptions of every other manner of fact.

\section{Study}

\subsection{Overview}

We designed a study to test the hypothesis that cultural cognition shapes perceptions of scientific consensus. That study involved two parts. The first was a correlational one, in which we measured culturally diverse subjects' perceptions of scientific consensus. The aim was to test whether distribution of views of scientific consensus across diverse issues fit the pattern one would expect on the basis of the type of cultural availability effect described in the last section. The second part of the study was an experiment designed to test for the existence of a particular mechanism that would explain how members of culturally diverse groups could end up forming opposing mental inventories of expert opinion. Using a between-subjects design, the experiment examined whether subjects' perceptions of an information source's expertise is conditional on the fit between the subjects' predispositions and the position that the putative expert espouses on a particular risk.

\subsection{Methods}

\subsubsection{Sample}

The study was administered on-line to a broadly representative sample of 1,500 U.S. adults between July 20 and July 28, 2009. Subjects were recruited by Polimetrix, Inc., a public opinion research firm that conducts on-line surveys and experiments on behalf of academic and governmental researchers and commercial customers (including political campaigns). Polimetrix used stratification methods designed to generate a sample demographically comparable to the adult U.S. population. The response rate was $55.5 \%$. The final sample was $54 \%$ female, $71 \%$ white, and $11.3 \%$ African-American. The average age was 47 years. Median household income for the sample was $\$ 40,000$ to $\$ 49,000$, and the median educational level was "some college.", 


\subsubsection{Cultural Worldview Measures}

We measured subjects' cultural values with items used in previous studies of cultural cognition (Kahan, Braman, Cohen, Gastil \& Slovic in press; Kahan, Braman, Gastil, Slovic \& Cohen 2009; Kahan, Braman, Gastil, Slovic \& Mertz 2007). ${ }^{2}$ These items characterize subjects' cultural worldviews along two cross-cutting dimensions: Hierarchy-egalitarianism ("Hierarchy") and Individualism-communitarianism ("Individualism"). The former set of items indicate attitudes toward social orderings that connect authority to stratified social roles based on highly conspicuous and largely fixed characteristics such as gender, race, and class (e.g., "Society as a whole has become too soft and feminine"; "We need to dramatically reduce inequalities between the rich and the poor, whites and people of color, and men and women"). The latter indicate attitudes toward social orderings that expect individuals to secure their own well-being without assistance or interference from society versus those that assign society the obligation to secure collective welfare and the power to override competing individual interests (e.g., "The government interferes far too much in our everyday lives"; "The government should do more to advance society's goals, even if that means limiting the freedom and choices of individuals"). For all items, subjects indicated agreement or disagreement on a six-point scale.

For this study, we used short-form versions of Hierarchy and Individualism, each of which consisted of six items. ${ }^{3}$ Like the full-form versions, the two six-item sets formed reliable scales (Hierarchy, $\alpha$ $=0.87$; Individualism, $\alpha=0.81$ ), the items of which loaded appropriately on two separate factors, which were used as predictors for the study.

\subsubsection{Correlational Component: Measures and Hypotheses}

Subjects were instructed to "read a series of statements" and indicate with respect to each "whether you think most expert scientists agree with the statement, most expert scientists disagree with

\footnotetext{
2 These items present refinements designed to respond to various criticisms of measures historically used in the cultural theory of risk (Marris, Langford \& O’Riordan 1998; Sjöberg 1998; Sjöberg 1997; Kahan, in press).

3 The cultural worldview items used for the study, along with other items from the study instrument, are reproduced in the Appendix.
} 
the statement, or expert scientists are divided in their views." The list (without the item identifiers) included:

GWREAL. Global temperatures are increasing.

GWHUMAN. Human activity is causing global warming.

NUKE. Radioactive wastes from nuclear power can be safely disposed of in deep underground storage facilities.

GUN. Permitting adults without criminal records or histories of mental illness to carry concealed handguns in public decreases violent crime.

These statements were selected on two grounds. First, they embody risk assessments or (in the case of climate change) risk-related facts over which culturally diverse subjects were expected to disagree. In previous studies, Hierarchy and Individualism had been shown to predict a propensity to believe that so-called "concealed carry" laws reduce the risk of crime, and a propensity to disbelieve that climate change and nuclear power present environmental dangers (Kahan, Braman, Gastil, Slovic \& Mertz 2007). Consistent with the "cultural availability" hypothesis, then, we predicted that individuals who are relatively hierarchical and individualistic would be more disposed than ones who are relatively egalitarian and communitarian to have formed the impression that "most expert scientists agree" with the statement expressed in GUN and that "most expert scientists disagree" with the statements expressed in GWREAL, GWHUMAN, and NUKE.

Second, each of these statements reflected a position either in line or at odds with a U.S. National Academy of Sciences "expert consensus report." An NAS report has endorsed the propositions reflected in GWREAL and GWHUMAN (National Research Council Committee on Analysis of Global Change Assessments 2007). Accordingly, we expected that with respect to these statements egalitarian and communitarian subjects would be the ones more likely to report impressions-“most expert scientists agree"-consistent with the NAS "expert consensus" positions. The NAS has also issued a report endorsing the proposition reflected in NUKE (National Research Council, Board on Radioactive Waste Management 1990). Here, then, we expected relatively hierarchical and individualistic subjects to be more likely to form the impression - again, "most expert scientists agree"- that was reflected in an NAS "expert consensus" report. On the effect of "concealed carry" laws, the NAS has issued a report finding (over 
one dissent, which took a position consistent with GUN) that the numerous econometric studies on the issue permitted no confident conclusion either way on whether such laws increase or decrease crime (National Research Council Committee to Improve Research Information and Data on Firearms 2004). Accordingly, we predicted that with respect to GUN, egalitarian communitarians and hierarchical individualists would both be inclined to report impressions of expert opinion inconsistent with the NAS "expert consensus report" but in opposing directions ("most . . . disagree" and "most . . agree," respectively).

We wanted to form hypotheses about culturally valenced beliefs that could be compared to positions reflected in NAS "consensus reports" to help validate our interpretation of results from the correlational part of the study. As explained, we anticipated that the impressions formed by hierarchical and individualistic subjects, on the one hand, and by relatively egalitarian and communitarian ones, on the other, would selectively converge and diverge from NAS "expert consensus" positions in a pattern consistent with these groups' respective predispositions toward risk. The NAS reports might themselves, of course, be imperfect reflections of the predominant opinion of expert scientists. But if subjects' cultural predispositions better predict their impressions of scientific opinion than do the NAS "expert consensus reports," we believe it is more plausible to infer that both hierarchical individualists and egalitarian communitarians are fitting their perceptions of scientific consensus to their predispositions than that either has some advantage over the other in discerning what "most expert scientists" really believe.

We did not form hypotheses about the exact size of the disparities of the perceptions of expert consensus on these issues. Nevertheless, consistent with the proposition that cultural dissensus on risk derives from culturally opposing perceptions of expert consensus, we did predict that in no case would a majority of subjects holding either hierarchical and individualistic values or egalitarian and communitarian ones report believing that "most expert scientists" disagreed with the position associated with these groups' respective predispositions. In addition, we predicted that differences in the perceptions of consensus associated with holding of these respective combinations values would be of a magnitude comparable to the levels of disagreement surrounding these issues outside of the laboratory, thereby furnishing support for the inference that culturally grounded differences in beliefs about the state of scientific opinion make a real-world contribution to such dissensus. 


\subsubsection{Experimental Component: Measures and Hypotheses}

In the experimental component of the study, each subject was instructed to "[i]magine a close friend told you he or she was undecided on" the risks associated with climate change, geologic isolation of nuclear waste, or concealed carry laws.

The friend tells you that he or she is planning to read a book about the issue but before taking the time to do so would like to get your opinion on whether the author seems like a knowledgeable and trustworthy expert.

The subject was shown a picture of the (fictional) author, who was depicted as a member of the National Academy of Sciences who had earned a Ph.D. in a pertinent field from one elite university and who was now on the faculty of another (Figure 1). In addition, the subject was shown an excerpt from the author's book, the position of which on the risk issue in question - whether the risk was high or low, well-founded or speculative-was randomly manipulated (Figure 2). The subject then indicated on a six-point scale how strongly he or she disagreed or agreed with the statement,

"I believe the author is a trustworthy and knowledgeable expert on ["global warming," "“"nuclear power," or "gun control"].

The hypothesis for the experiment was that the likelihood of agreement that the featured author was a trustworthy and knowledgeable expert would be conditional on the fit between the author's assigned position and subjects' own cultural predispositions on the issue in question. Hence, the more hierarchical and individualist individuals were, the more likely they would be to agree, and the more egalitarian and communitarian the less likely they would be to agree, when the author was assigned the "low risk" position on either climate change, nuclear waste disposal, or concealed carry laws. We expected the patterns to be revered when the author was assigned the "high risk" position. 


\section{Is this a knowledgeable and credible expert on ...?}

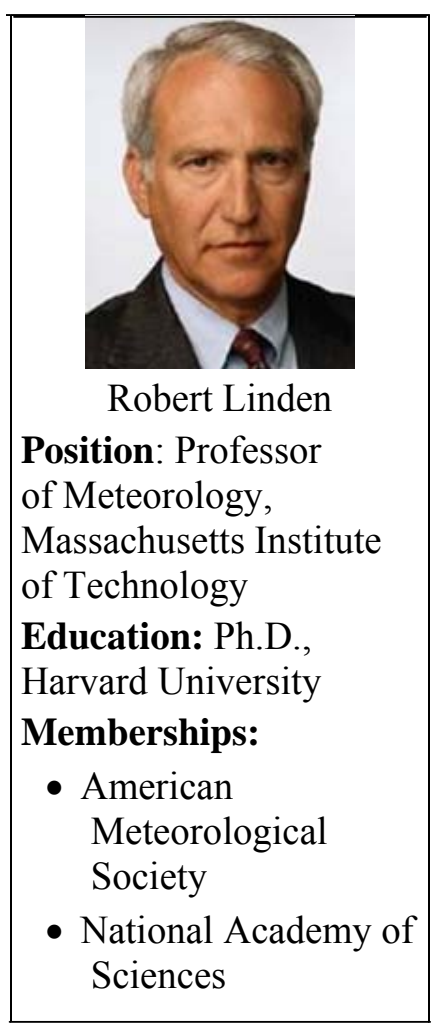

Global Warming

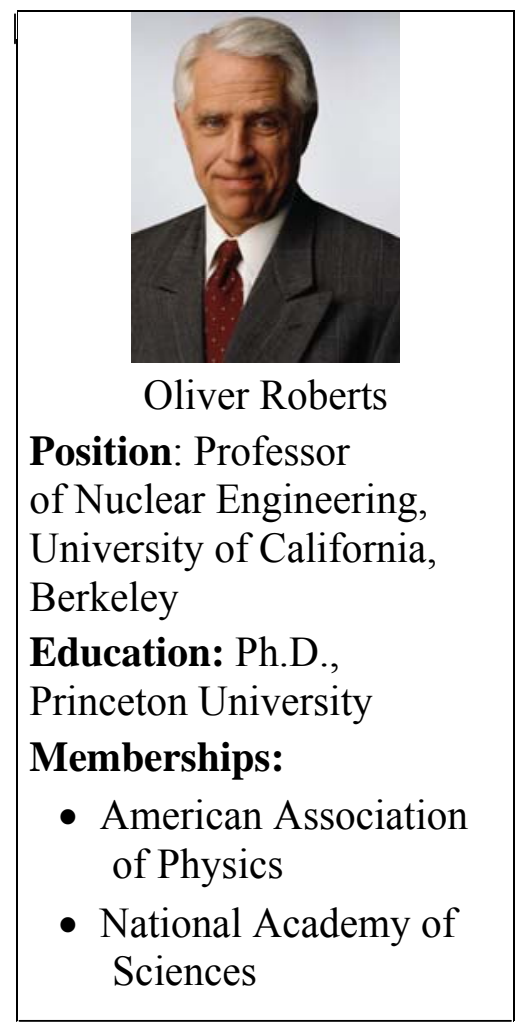

Nuclear Power

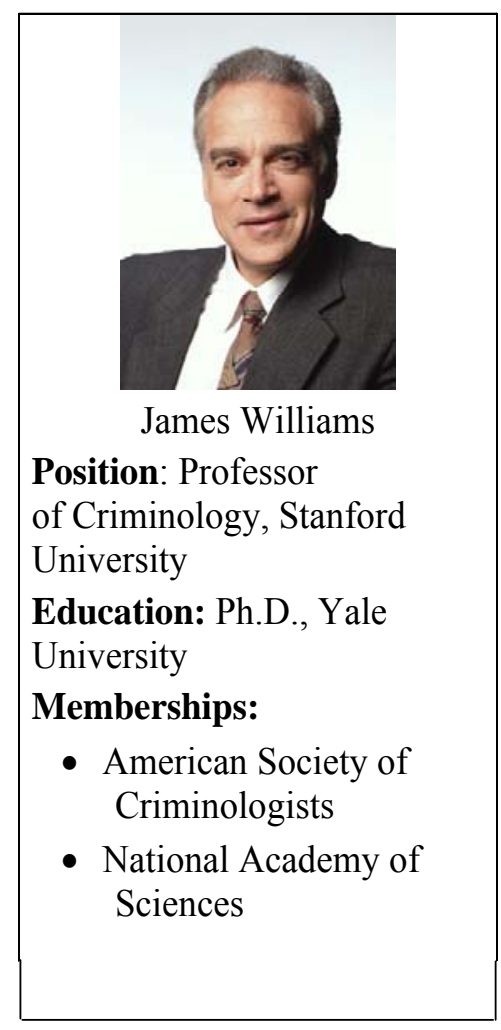

Gun Control

Figure 1. Fictional book authors. These fictional individuals were identified as the authors of books on the risks of climate change, of nuclear power generation, and of laws permitting citizens to carry concealed handguns in public. The position they took on those risks, as reflected in book excerpts (Figure 2) was experimentally manipulated, and subjects were instructed to indicate whether they agreed or disagreed that the pictured individual was a knowledgeable and trustworthy expert. 
High Risk

"It is now beyond reasonable scientific dispute that human activity is causing 'global warming' and other dangerous forms of climate change. Over the past century, atmospheric concentration of carbon dioxide $\left(\mathrm{CO}_{2}\right)$-called a "greenhouse gas" because of its contribution to trapping heat - has increased to historically unprecedented levels. Scientific authorities at all major universities agree that the source of this increase is human industrial activity. They agree too that higher $\mathrm{CO}_{2}$ levels are responsible for steady rises in air and ocean temperatures over that period, particularly in the last decade. This change is resulting in a host of negative consequences: the melting of polar ice caps and resulting increases in sea levels and risks of catastrophic flooding; intense and long-term droughts in many parts of the world; and a rising incidence of destructive cyclones and hurricanes in others."

"Using deep geologic isolation to dispose of radioactive wastes from nuclear power plants would put human health and the environment at risk. The concept seems simple: contain the wastes in underground bedrock isolated from humans and the biosphere. The problem in practice is that there is no way to assure that the geologic conditions relied upon to contain the wastes won't change over time. Nor is there any way to assure the human materials used to transport wastes to the site, or to contain them inside of the isolation facilities, won't break down, releasing radioactivity into the environment.... These are the sorts of lessons one learns from the complex problems that have plagued safety engineering for the space shuttle, but here the costs of failure are simply too high.

\footnotetext{
"So-called 'concealed carry' laws increase violent crime. The claim that allowing people to carry concealed handguns reduces crime is not only contrary to common-sense, but also unsupported by the evidence. ... Looking at data from ing handguns in public went from having the highest rates of rape and property offenses to having the lowest rates of those crimes... .To put an economic price tag on the issue, I estimate that the cost of "concealed carry laws" is around $\$ 500$ million a year in the U.S."
} Concealed Fire- 1977 to 2005, the 22 states that prohibited carryarms
Low Risk

"Judged by conventional scientific standards, it is premature to conclude that human $\mathrm{CO}_{2}$ emissions-so-called 'greenhouse gasses'-cause global warming. For example, global temperatures have not risen since 1998, despite significant increases in $\mathrm{CO}_{2}$ during that period. In addition, rather than shrinking everywhere, glaciers are actually growing in some parts of the world, and the amount of ice surrounding Antarctica is at the highest level since measurements began 30 years ago... . Scientists who predict global warming despite these facts are relying entirely on computer models. Those models extrapolate from observed atmospheric conditions existing in the past. The idea that those same models will accurately predict temperature in a world with a very different conditions - including one with substantially increased $\mathrm{CO}_{2}$ in the atmosphere-is based on unproven assumptions, not scientific evidence. ..."

\begin{abstract}
"Radioactive wastes from nuclear power plants can be disposed of without danger to the public or the environment through deep geologic isolation. In this method, radioactive wastes are stored deep underground in bedrock, and isolated from the biosphere for many thousands of years. Natural bedrock isolation has safely contained the radioactive products generated by spontaneous nuclear fission reactions in Oklo, Africa, for some 2 billion years. Man-made geologic isolation facilities reinforce this level of protection through the use of sealed containers made of materials known to resist corrosion and decay. This design philosophy, known as 'defense in depth,' makes long-term disposal safe, effective, and economically feasible."
\end{abstract}

\begin{abstract}
“Overall, 'concealed carry' laws decrease violent crime. The reason is simple: potential criminals are less likely to engage in violent assaults or robberies if they think their victims, or others in a position to give aid to those persons, might be carrying weapons. . . . Based on data from 1977 to 2005, I estimate that states without such laws, as a group, would have avoided 1,570 murders; 4,177 rapes; and 60,000 aggravated assaults per year if they had made it legal for law-abiding citizens to carry concealed handguns. Economically speaking, the annual gain to the U.S. from allowing concealed handguns is at least $\$ 6.214$ billion."
\end{abstract}

Figure 2. Book excerpts attributed to fictional authors. One of two opposing excerpts were randomly assigned to fictional authors (Figure 1) whose expertise was evaluated by subjects.

Here too we did not form precise estimates of size of these effects. We did not anticipate, neces-

sarily, that majorities of either subjects with a hierarchical and individualistic worldview or ones with an

egalitarian and communitarian worldview would reject the proposition that the pictured author was an 
expert in the conditions in which the author was depicted as taking the position contrary to the one associated with their respective predispositions. However, we anticipated that manipulation of author positions would result in changes in the likelihood of agreement, within and across culturally defined groups, large enough to be considered practically and not merely statistically significant—ones that if observed in real-world settings would plausibly be expected to generate noticeable and consequential levels of disagreements among persons of diverse values.

\subsubsection{Covariates}

Data were collected on a full range of additional demographic characteristics, including gender, race, education level, income, political ideology, and party affiliation. It was anticipated that these variables would be used in controls in multivariate testing of the results of the two study components.

\subsubsection{Statistical Analyses, Power, and Missing Data}

We anticipated analyzing results of both study components in two steps. The first would consist of preliminary analyses of response frequencies across culturally defined groups. To enable comparison of the groups most pertinent to the study hypotheses, subjects whose cultural worldview scores placed them in the top half of both the Hierarchy and Individualism scales were designated "hierarchical individualists," and those whose scores placed in the bottom half of both were designated "egalitarian communitarians."

In the second step, multivariate analyses, including multinomial and ordered logistical regression, were to be used for more definitive testing of the study hypotheses. In these analyses, we planned to use the culture scales as continuous predictors of variance across the sample as a whole in order to maximize statistical power (Judd, 2000, p. 372; Jaccard \& Turrisi, 2003, p. 86). To measure the hypothesized effect of relevant combinations of cultural worldviews, a product interaction term, Hierarchy $\mathrm{x}$ Individualism, was created (Aiken, West \& Reno 1991). We anticipated performing Monte Carlo simulations, based on the regression analyses, to estimate the effects of holding either hierarchical and individualistic values or egalitarian and communitarian ones (Gellman \& Hill 2007; King, Tomz \& Wittenberg 2000). The size of the sample furnished adequate power to detect even small effect sizes (e.g., $r=.10)$ with a probability well over .80 at $p \leq .05$ (Cohen 1988). As a result, findings of nonsignificance could be equated with lack 
of effect with low risk of Type II error (Streiner, 2003). To facilitate multivariate regression, missing data were replaced by multiple imputation (Rubin 2004; King, Honaker, Joseph \& Scheve 2001).

\section{Results}

\subsection{Correlational Component of the Study}

\subsubsection{Simple Frequencies}

Preliminary analyses of the correlational component are reported in Figure 3 and Figure 4. A majority $-55 \%$ - of the subjects reported perceiving that a majority of expert scientists agree that global temperatures are rising, while 33\% reported perceiving division; on whether humans are causing global warming, $45 \%$ perceived that expert scientific agreement with that proposition, while $40 \%$ reported perceiving that scientists were divided. Pluralities perceived that experts were divided on the safety of geologic isolation of nuclear wastes (46\%) and the crime-reducing impact of concealed carry laws (41\%), with roughly a quarter $(25 \%, 26 \%$, respectively) perceiving scientific agreement with those positions roughly a third (29\% and 33\%, respectively) perceiving that most expert scientists disagree with them.

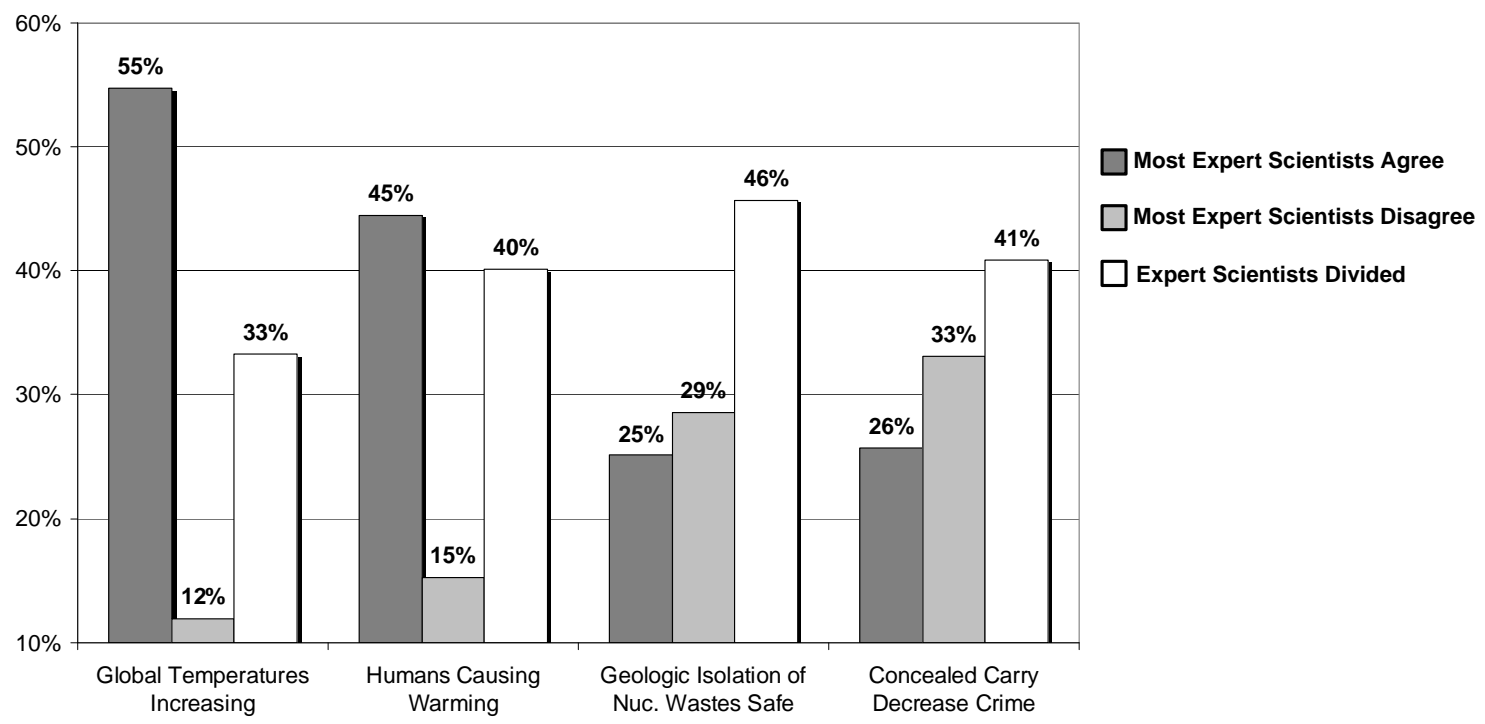

Figure 3. Overall sample frequencies on perceptions of scientific opinion. $N=1491-1498$. Bars indicate percentage of subjects who selected "most expert scientists agree," "most expert scientists disagree," and "expert scientists are divided in their views" on indicated risk position.

Disagreement was sharp among individuals identified (through median splits along both dimensions of cultural worldview) as "hierarchical individualists," on the one hand, and "egalitarian communi- 
tarians," on the other. Solid majorities of egalitarian communitarians perceived that most expert scientists agree that global warming is occurring (78\%) and that it has an anthropogenic source $(68 \%)$. In contrast, $56 \%$ of hierarchical individualists believe that scientists are divided, and another $25 \%$ (as opposed to $2 \%$ for egalitarian communitarians) that most expert scientists disagree that global temperatures are increasing. Likewise, a majority of hierarchical individualists, 55\%, believed that most expert scientists are divided on whether humans are causing global warming, with another $32 \%$ perceiving that most expert scientists disagree with this conclusion. These patterns conformed to the study hypotheses.

The cultural division on perceptions of expert opinion on concealed carry laws also conformed to the study hypotheses. A plurality of hierarchical individualists (47\%) perceived that most expert scientists agree, a plurality of egalitarian communitarians (47\%) that most expert scientists disagree, that permitting citizens to carry handguns in public reduces crime. Only $10 \%$ of hierarchical individualists perceived that expert scientists disagree with this position, and only $12 \%$ of egalitarian communitarians that they agree with it. Comparable proportions of both types (hierarchical individualists, 40\%; egalitarian communitarians, $42 \%$ ) perceived that expert scientists are divided on this issue. 


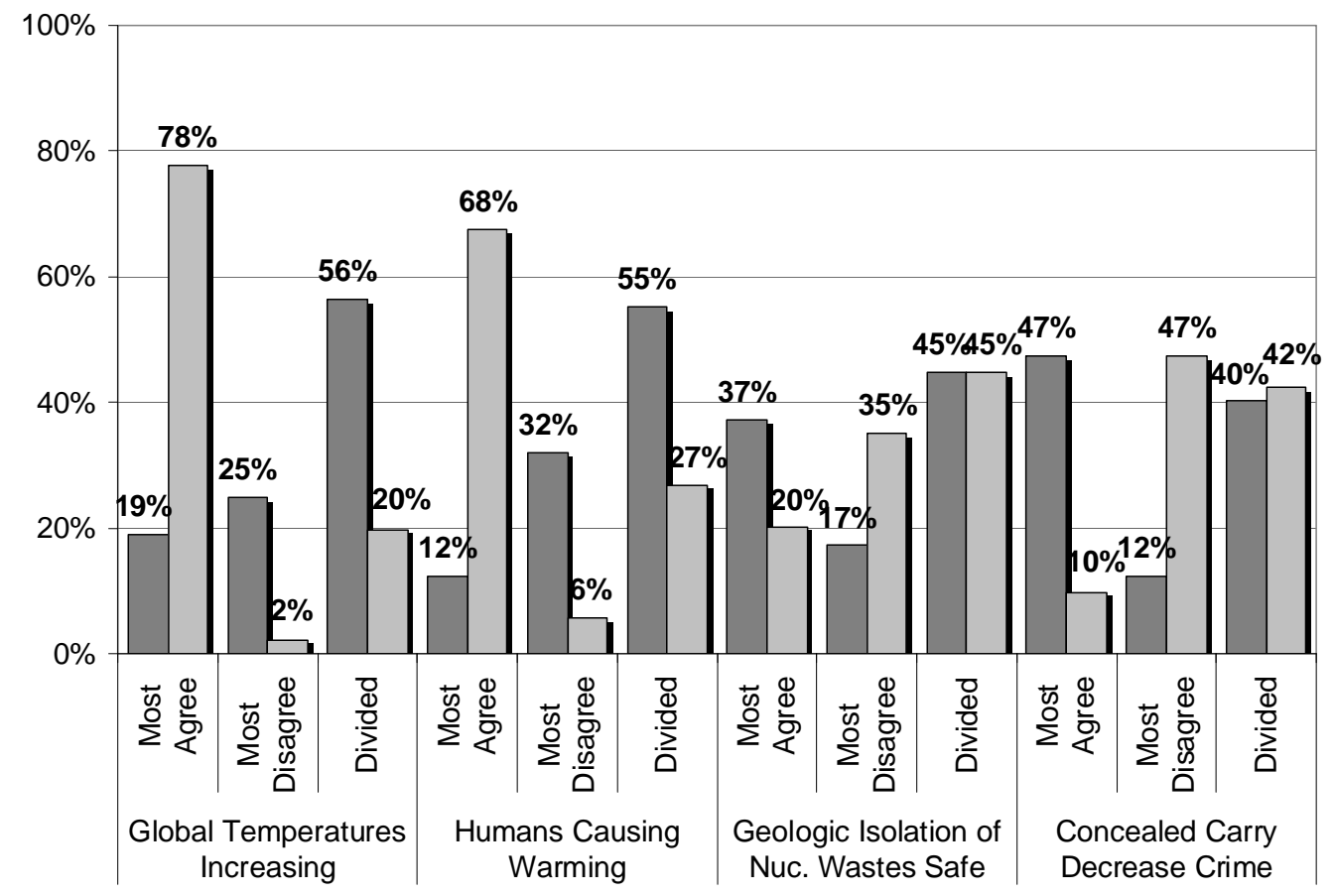

Figure 4. Frequencies by culture type on perceptions of scientific opinion. $N=746-749$. Bars indicate percentage of subjects of specified combination of cultural worldviews (as determined by subjects' scores on Hierarchy and Individualism relative to sample medians) who selected "most expert scientists agree," "most expert scientists disagree," and "expert scientists are divided in their views" on indicated risk position.

On the safety of geologic isolation of nuclear wastes, a plurality of both hierarchical individualists (45\%) and egalitarian communitarians (45\%) perceived that expert scientists are divided. Consistent with the study hypotheses, however, varying proportions of each type reported perceiving scientific consensus on one or the other side of this debate. Thus, egalitarian communitarians were about twice as likely as hierarchical individualists (35\% to $17 \%$ ) to report that "most expert scientists disagree," and only a little more than half as likely ( $20 \%$ to $37 \%$ ) to report that "most expert scientists agree," that geologic isolation of nuclear wastes is safe.

\subsubsection{Multivariate Analyses}

The results of the correlational part of the study were more systematically assessed through a set of multinomial logistic regression analyses (Table 1). In each, the response to the scientific opinion measure for the specified risk item was regressed against two sets of variables: first, the covariates selected as control variables; and second, those covariates plus Hierarchy, Individualism, and the interaction term 
Hierarchy $\mathrm{x}$ Individualism. The cultural variables were entered into the analyses as a block because the study hypotheses posited that Hierarchy and Individualism would influence perceptions jointly (through their sum and interaction) rather than independently of one another (Cohen, Cohen, West \& Aiken, pp. 162-70, 2003).

The significant $G$-statistic associated with the second step of each regression analysis indicates that subjects' cultural worldviews explain a statistically significant degree of variation in their responses holding the covariates constant (Cohen, Cohen, West \& Aiken, pp. 504-05, 508-09, 2003). It is difficult, however, to determine the fit between the multivariate analyses and the study hypotheses from the face of the regression output. The sign and effect of the cultural variables - which must be aggregated in a manner that reflects the hypotheses - cannot be readily inferred from simple examination of the coefficients for the two cultural variables and the product interaction term. Moreover, the regression outputs reflect only the impact of the cultural variables on "most expert scientists disagree" and "expert scientists are divided" responses, respectively, relative to the baseline response, "most experts agree"; the study hypotheses also require assessing the impact of cultural worldviews on the "most agree" and "divided" responses relative to one another. The most straightforward way to discern the nature of all of these effects and to assess their statistical and practical significance is through statistical simulation based on the regressions (Gellman \& Hill, pp. 141-42, 2007; King, Tomz, \& Wittenberg 2000).

Simulation results are reflected in Figure 5. The results reflect how much more likely, all else equal, a subject with one combination of cultural values is to select the indicated response than is a subject with the opposing combination (determined by simulating responses when the relevant cultural worldview predictors are set one standard deviation from the mean in the indicated directions; the product interaction terms to the corresponding values; and all other predictors to their means (Gellman \& Hill, pp. 178-81, 2007)). Thus, holding other influences constant, being simultaneously hierarchical and individualistic as opposed to simultaneously egalitarian and communitarian results in a decrease of 56.9 percentage points ( \pm 8.5 percentage points $)$ in the likelihood that an individual will perceive that "most expert scientists agree" that "[g]lobal temperatures are increasing." A person holding hierarchical and individualistic outlooks is 59.2 percentage points more likely $( \pm 8.2)$ than one holding egalitarian and communitarian 
outlooks to perceive that "most expert scientists agree" that "[h]uman activity is causing global warming." Being hierarchical and individualistic also predicts a significantly greater likelihood in perceiving that "most expert scientists disagree" or are "divided" on these questions. These results are consistent with the study hypotheses.

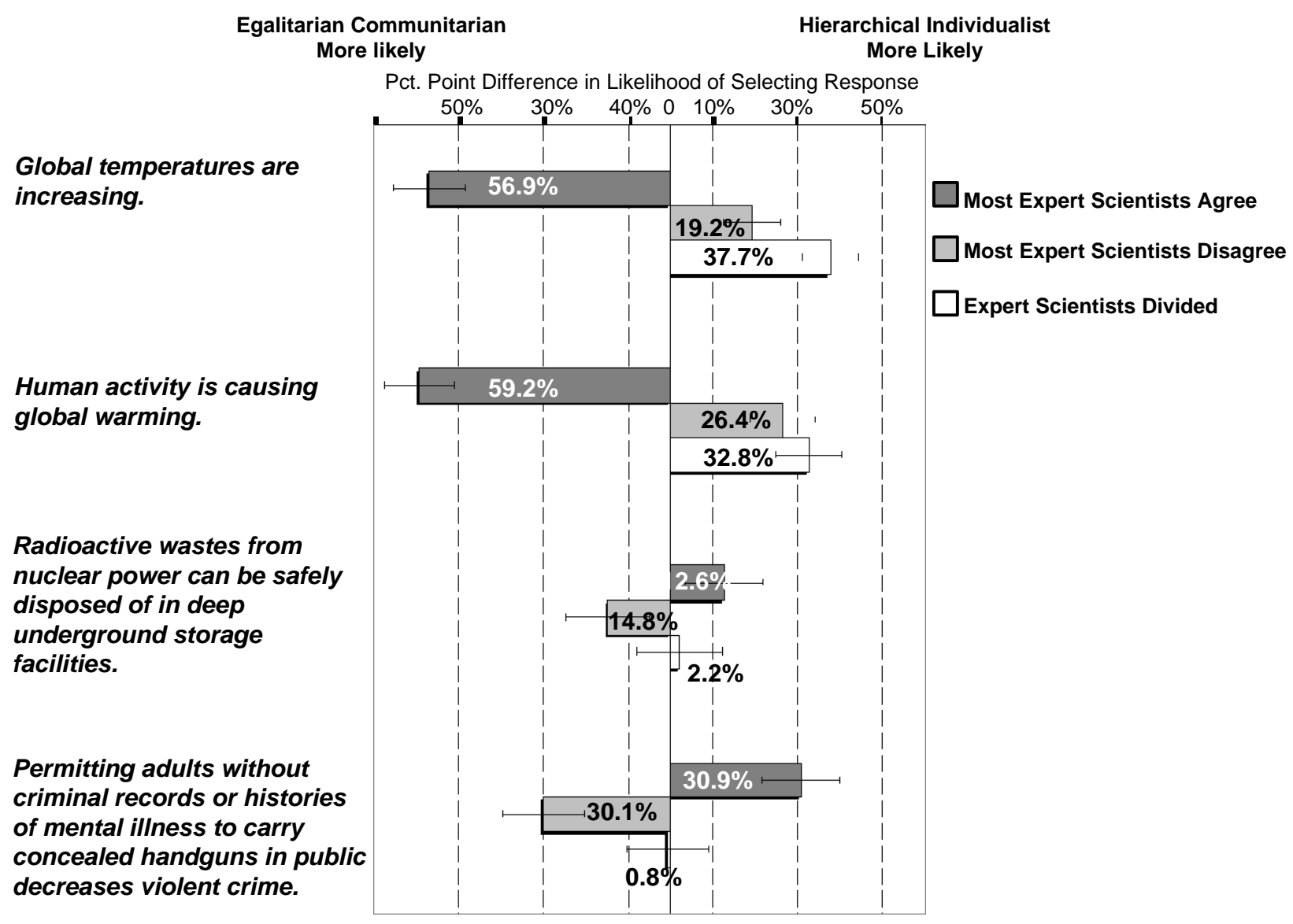

Figure 5. Differential impact of cultural worldviews on perceptions of expert consensus. $N=1500$. Derived from multinomial regression analysis (Table 1). Bars indicate how much more likely a subject with the indicated worldview is than a subject with the opposing worldview to select indicated response (holding other individual characteristics constant). Cultural worldviews reflect values one standard deviation from the mean in the indicated directions on the "hierarchy-egalitarian" and "individualist-communitarian" scales. Confidence intervals reflect .95 level of confidence. 
GWREAL

GWHUMAN

NUKE

GUN

Most Expert Scientists Disagree

Male (vs. Female)

Step $1 \quad$ Step 2

Step $1 \quad$ Step 2

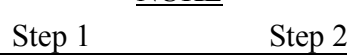

Step 1

Step 2

White (vs. Black)

.39 (.19)

$.00 \quad(.20)$

$.21 \quad(.18)$

$-.17 \quad(.19)$
-1.04

$\begin{array}{rr}-.81 & (.15)\end{array}$

$-70 \quad(15)$

Nonwhite (vs. Black)

Age

Household Income

Education

No Religion (vs. some)

Church Attendance

Democrat (vs. Repub)

Ind. (vs. Repub)

Other Party (vs. Repub)

$\mathrm{Lib}=>$ Conservative

$01 \quad(.37)$

$\mathbf{- 1 . 0 7}(.41)$

$-.07 \quad(.31)$

$\mathbf{- 1 . 0 4}(.34)$

$.07 \quad(.24)$

$.05 \quad(.35)$

$.00 \quad(.01)$

$-.01 \quad(.01)$

$.06 \quad(.03)$

$-.13 \quad(.07)$

$.28 \quad(.27)$

.19 (.08)

$-.26 \quad(.23)$

$.35 \quad(.35)$

-1.23 (.32)

.87

$.02 \quad(.03)$

$-.09 \quad(.07)$
.33

$.33 \quad(.28)$

$.17 \quad(.08)$

$-.17 \quad(.24)$
.44

$.44 \quad(.37)$

$\begin{array}{ll}-.76 & (.35)\end{array}$

$.41 \quad(.13)$

1.16 (.70)

$.24 \quad(.75)$

$\begin{array}{ll}.00 & (.01) \\ .05 & (.03)\end{array}$

-.62 (.37)

$.09 \quad(.28)$

$.35 \quad(.25)$

$-.01 \quad(.01)$
.02

$.00 \quad(.01)$

-.19 (.07)

$-.34 \quad(.26)$

$.13 \quad(.07)$

$-.20 \quad(.23)$

$.51 \quad(.33)$

$-.93 \quad(.28)$

$.77 \quad(.10)$

$.02 \quad(.03)$

$-.05 \quad(.03)$

$-.13 \quad(.07)$

$-.32 \quad(.27)$

$-.01 \quad(.06)$

$.16 \quad(.20)$

$.12 \quad(.08)$

$-.07 \quad(.24)$

$-.08 \quad(.07)$

$.15 \quad(.21)$

$.57 \quad(.37)$

$-.10 \quad(.35)$

$.28 \quad(.24)$

$\begin{array}{rr}-.36 & (.31) \\ 30 & (.11)\end{array}$

$-.25 \quad(.09)$

$.49 \quad(.61)$

$-.20 \quad(.63)$

Individ

$.05 \quad(.13)$

$.16 \quad(.11)$

$.30 \quad(.29)$
$.00 \quad(.01)$

$.00 \quad(.01)$

$-.04 \quad(.03)$

$-.04 \quad(.06)$

$.13 \quad(.20)$

$-.06 \quad(.07)$

$.10 \quad(.21)$

$-.15 \quad(.35)$

$.10 \quad(.24)$

$-.07 \quad(.10)$

$.10 \quad(.42)$

$.50 \quad(.42)$

$-.11 \quad(.08)$

$\begin{array}{llll}-.80 & (.16) & -.62 & (.16)\end{array}$

$.12 \quad(.26)$

$.67 \quad(.28)$

$.57 \quad(.31)$

$.97 \quad(.32)$

Hierarch x Individ

$29 \quad(.13)$

Expert Scientists Dividec

$\begin{aligned} .29 & (.13) \\ .19 & (.22) \\ -.13 & (.26) \\ .01 & (.00) \\ .03 & (.02) \\ -.10 & (.05) \\ .31 & (.17) \\ .13 & (.06) \\ -.36 & (.17) \\ -.09 & (.29) \\ -.90 & (.19) \\ .48 & (.07)\end{aligned}$

$.00 \quad(.00)$

$.17 \quad(.13)$

$-.04 \quad(.13)$

$.08 \quad(.20)$

White (vs. Black)

Nonwhite (vs. Black)

Age

Household Income

Education

No Religion (vs. some)

Church Attendance

Democrat (vs. Repub)

Ind (vs. Repub)

Other Party (vs. Repub)

$\mathrm{Lib}=>$ Conservative

$.06 \quad(.14)$

$-.11 \quad(.24)$

$\begin{array}{ll}-.42 & (.21) \\ -.42 & (.24)\end{array}$

$.00 \quad(.00)$

$.02 \quad(.02)$

$.00 \quad(.00)$

$.00 \quad(.02)$

$.00 \quad(.00)$

$-.07 \quad(.05)$

$.10 \quad(.16)$

$\begin{array}{ll}-.02 \quad(.05) \\ .14 & (.17)\end{array}$

$.01 \quad(.02)$

$\begin{array}{rr}. .06 & (.05) \\ .39 & (.18)\end{array}$

$.06 \quad(.06)$

$-.47 \quad(.18)$

$-.43 \quad(.31)$

$.14 \quad(.17)$

$\begin{array}{rr}.13 & (.06) \\ -.25 & (.18)\end{array}$

$\begin{array}{ll}-.05 \quad(.31) \\ -.51 & (.21)\end{array}$

-1.08 (.20)

$.06 \quad(.06)$

$\begin{array}{ll}-.32 \quad(.19) \\ -.35 & (.33)\end{array}$

$\begin{array}{ll}-.35 \quad(.33) \\ -.66 & (.21)\end{array}$

$.41 \quad(.07)$

-.66 (.21)

$.11 \quad(.08)$

$.35 \quad(.36)$

$.17 \quad(.09)$

$\begin{array}{ll}-.10 \quad(.40) \\ -.45 & (.40)\end{array}$

Individ

$-.45 \quad(.40)$

$.06 \quad(.35)$

$.09 \quad(.07)$

Hierarch x Individ

$\mathbf{5 3 4 . 8 5}$

147.05

345.84

503.49
157.65

$\begin{aligned}-.57 & (.14) \\ .25 & (.23) \\ .10 & (.27) \\ .00 & (.00) \\ -.05 & (.02) \\ .04 & (.05) \\ .32 & (.19) \\ .02 & (.06) \\ .06 & (.18) \\ .12 & (.28) \\ -.08 & (.21) \\ -.23 & (.08) \\ & \end{aligned}$

$-.49 \quad(.14)$

$\begin{array}{rr}-.49 & (.14) \\ .42 & (.24)\end{array}$

$.25 \quad(.27)$

$.00 \quad(.00)$

$\begin{aligned}-.05 & (.02)\end{aligned}$

$.03 \quad(.05)$

$.31 \quad(.19)$

$.03 \quad(.06)$

$.05 \quad(.18)$

$.08 \quad(.28)$

$-.14 \quad(.22)$

$-.13 \quad(.09)$

$.42 \quad(.39)$

$.73 \quad(.40)$

$-.14 \quad(.08)$

$G$-test ( $\Delta$ likelihood ratio $\chi 2$ )

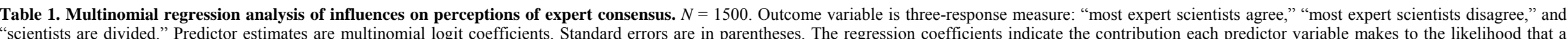

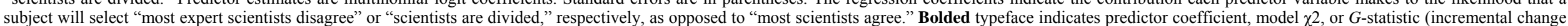
in model $\chi 2$ associated with additional predictors) is statistically significant at $p<0.05$. 
The simulation results for perceptions of scientific opinion on concealed handguns also fit the study hypotheses. Being egalitarian and communitarian predicted a 30.9 percentage-point increase $( \pm 9.1)$ in the likelihood of perceiving that "most expert scientists agree" that "[p]ermitting adults without criminal records or histories of mental illness to carry concealed handguns in public decreases violent crime," and a 30.1 percentage-point decrease $( \pm 9.7)$ in perceiving that "most disagree," relative to being hierarchical and individualistic. Again the difference in the perception that scientists are "divided" was not significant.

The significant difference in perceptions of expert consensus on nuclear waste disposal also persisted in the multivariate analysis. Being simultaneously hierarchical and individualistic predicts a 12.6 percentage-point increase $( \pm 9.2)$ in the likelihood of perceiving "most expert scientists agree" that "[r]adioactive wastes from nuclear power can be safely disposed of in deep underground storage facilities," and a 14.8 percentage-point decrease $( \pm 9.2)$ in the likelihood of perceiving that "most disagree." The difference in the predicted likelihood of perceiving that scientists are "divided" is not statistically (or practically) significant. Although clearly less dramatic in magnitude than the differences observed for perceptions of scientific opinion on climate change and concealed carry laws, the effects of cultural outlooks on perceptions of scientific opinion for nuclear waste disposal evidence a practically meaningful level of disagreement and conform to the hypothesized impact of holding either hierarchic and individualistic or egalitarian and communitarian worldviews.

\subsection{Experimental Component of the Study}

\subsubsection{Simple Frequencies}

Preliminary analyses of the experimental component are reported in Figure 6 and Figure 7. Figure 6 reports the overall sample frequencies, which show that a majority of subjects agreed that each of the pictured authors was a "trustworthy and knowledgeable expert."

Figure 7 presents frequencies of subjects identified by cultural type. The results again confirmed study hypotheses. 


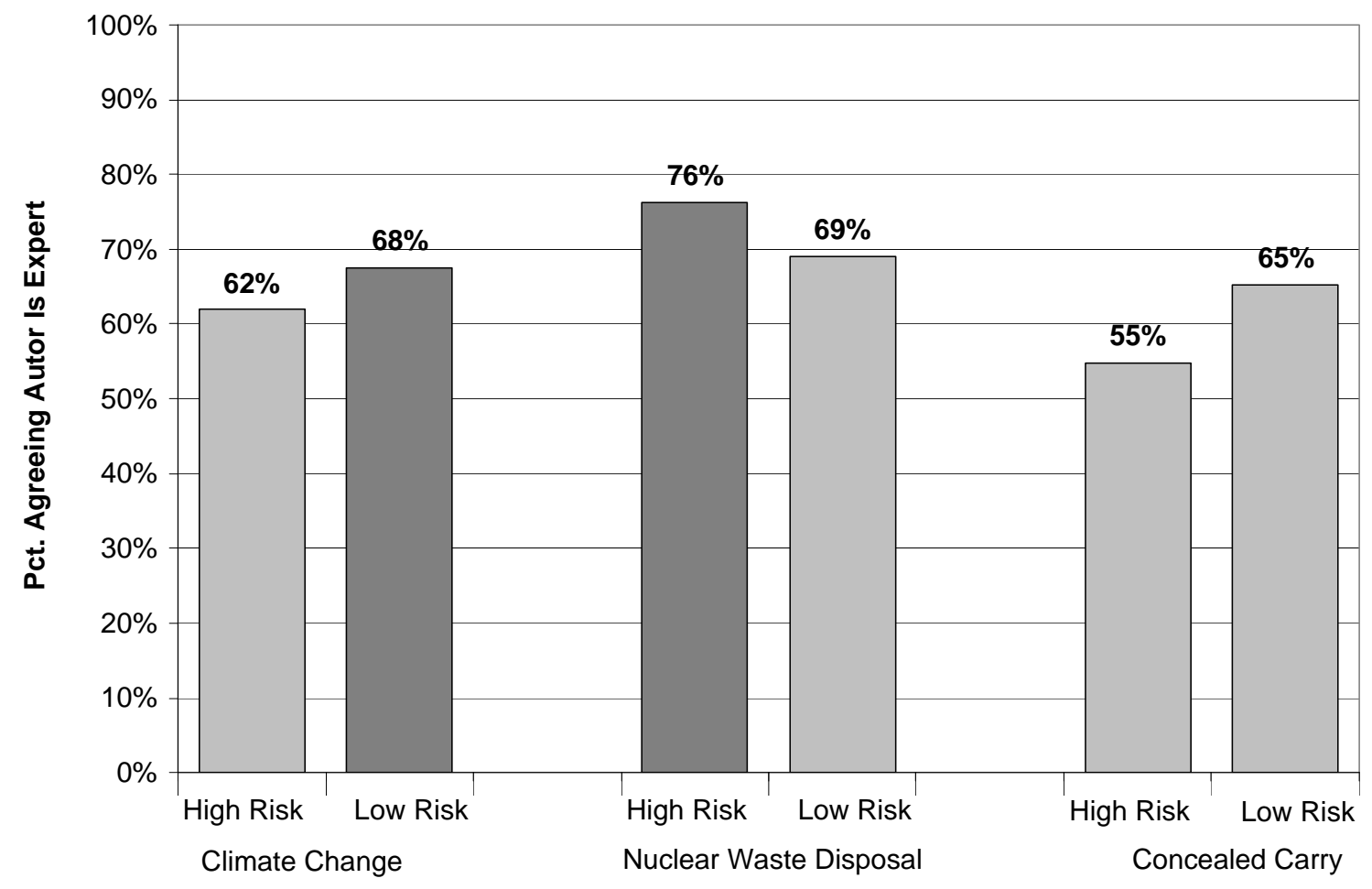

Author's Position

Figure 6. Overall sample frequencies on author expertise. $N=1492-1495$. Bars indicate percentage of subjects who agreed (either "slightly," "moderately," or "strongly") that the depicted author was a "trustworthy and knowledgeable expert" when assigned indicated position.

On global warming, the position imputed to the putative expert dramatically affected the responses of both hierarchical individualists and egalitarian communitarians. Eighty-eight percent of egalitarian communitarians, but only $23 \%$ of hierarchical individualists, agreed (either "slightly," "moderately," or "strongly") that the depicted author was a "trustworthy and knowledgeable expert" when the author was presented as supporting the "high risk" position. In contrast, when the depicted author was presented as supporting the "low risk" position, the proportion of hierarchical individualists who agreed the author was an expert climbed to $86 \%$, whereas the proportion of egalitarian communitarians who agreed dropped to $47 \%$.

The results were similar for the concealed-carry-law expert. When the depicted author was assigned the "high risk" position, egalitarian communitarians and hierarchical individualists were divided $80 \%$ to $23 \%$ on whether he was an expert. Agreement was again substantially higher among hierarchical 
individualists (85\%) and substantially lower among egalitarian communitarians $(50 \%)$ when the author was assigned the "low risk" position.

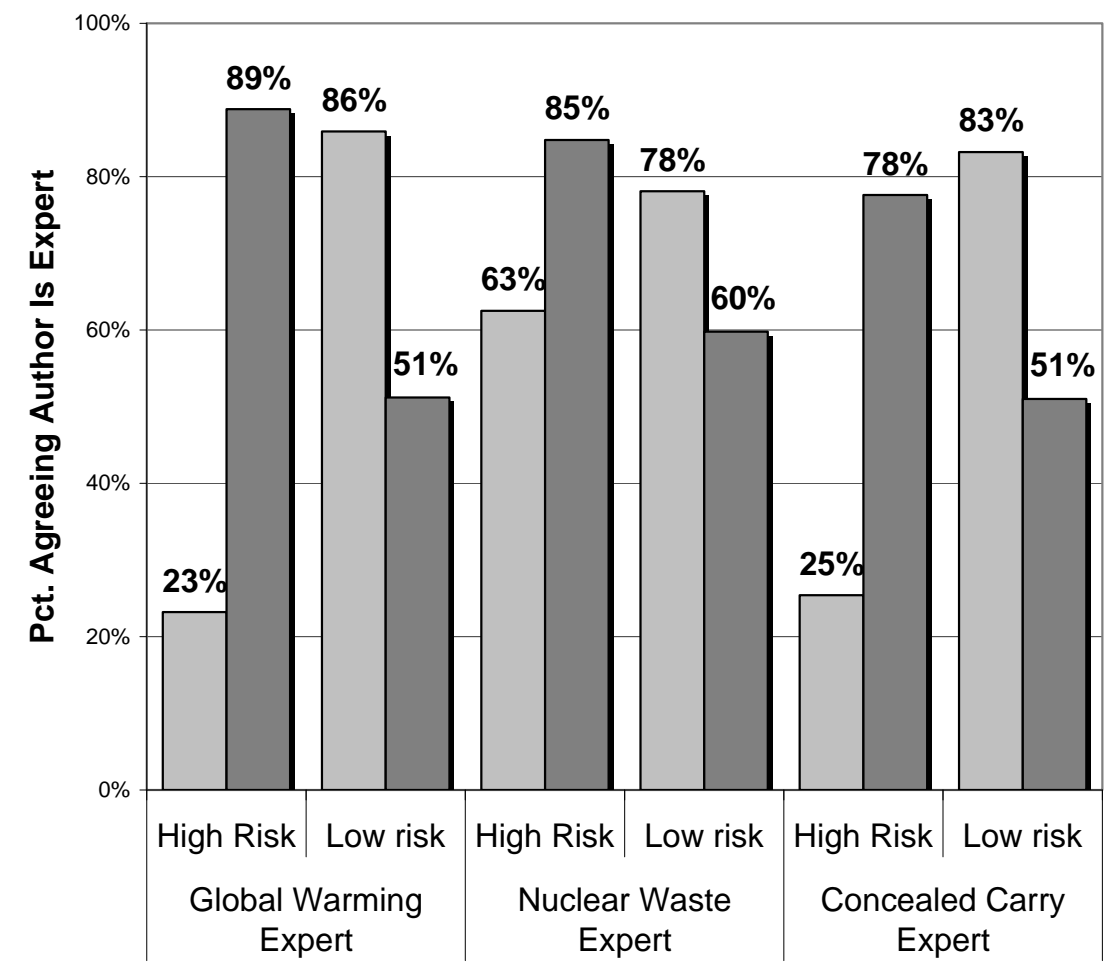

Figure 7. Frequencies by culture type on author expertise. $N=745-749$. Bars indicate percentage of subjects of specified combination of cultural worldviews (as determined by subjects' scores on Hierarchy and Individualism relative to sample medians) who agreed (either "slightly," "moderately," or "strongly") that the depicted author was a "trustworthy and knowledgeable expert" when assigned indicated position.

On nuclear waste disposal, the basic pattern was the same but less pronounced. egalitarian communitarians were more likely - by a margin of $84 \%$ to $61 \%$ - to perceive that the author was a "trustworthy and knowledgeable expert" when he was assigned the "high risk" position, whereas hierarchical individualists were more likely — by a margin of $78 \%$ to $57 \%$ - to agree when the author was assigned the "low risk" position. 


\begin{tabular}{|c|c|c|c|c|c|c|c|c|c|c|c|c|c|c|c|}
\hline \multirow[b]{3}{*}{ Risk $(0=$ low risk, $1=$ high $)$} & \multicolumn{5}{|c|}{ Global Warming } & \multicolumn{5}{|c|}{ Nuclear Waste Disposal } & \multicolumn{5}{|c|}{ Concealed Carry } \\
\hline & Step 1 & \multicolumn{2}{|c|}{ Step 2} & \multicolumn{2}{|c|}{ Step 3} & Step 1 & \multicolumn{2}{|c|}{ Step 2} & \multicolumn{2}{|c|}{ Step 3} & Step 1 & \multicolumn{2}{|c|}{ Step 2} & \multicolumn{2}{|c|}{ Step 3} \\
\hline & $\begin{array}{ll}-.31 & (.09)\end{array}$ & -.32 & $(.09)$ & 8.72 & $(2.78)$ & $.40 \quad(.09)$ & .40 & $(.09)$ & 2.41 & $(2.75)$ & $\begin{array}{ll}.47 & (.09)\end{array}$ & -.47 & $(.09)$ & 1.57 & $(2.69)$ \\
\hline Male (vs. Female) & & -.21 & $(.10)$ & -.18 & $(.10)$ & & -.07 & $(.10)$ & .00 & $(.10)$ & & -.07 & $(.10)$ & -.12 & $(.10)$ \\
\hline White (vs. Black) & & -.22 & $(.15)$ & -.07 & $(.16)$ & & .11 & $(.16)$ & .19 & $(.16)$ & & .13 & $(.15)$ & .09 & $(.16)$ \\
\hline Nonwhite (vs. Black) & & -.04 & $(.18)$ & .23 & $(.18)$ & & -.02 & $(.18)$ & .05 & $(.18)$ & & .14 & $(.18)$ & .07 & $(.18)$ \\
\hline Age & & .00 & $(.00)$ & .00 & $(.00)$ & & .00 & $(.00)$ & .00 & $(.00)$ & & -.01 & $(.00)$ & -.01 & $(.00)$ \\
\hline Household Income & & .01 & $(.02)$ & .01 & $(.02)$ & & -.02 & $(.01)$ & -.01 & $(.02)$ & & .03 & $(.02)$ & .02 & $(.02)$ \\
\hline Education & & .02 & $(.04)$ & -.01 & $(.04)$ & & .05 & $(.04)$ & .02 & $(.04)$ & & -.05 & $(.04)$ & -.03 & $(.04)$ \\
\hline No Religion (vs. some) & & -.15 & $(.12)$ & -.09 & (.13) & & .05 & $(.13)$ & .06 & (.13) & & -.13 & $(.12)$ & -.08 & (.13) \\
\hline Church Attendance & & -.06 & $(.04)$ & -.07 & $(.04)$ & & -.04 & $(.04)$ & -.04 & $(.04)$ & & .00 & $(.04)$ & -.04 & $(.04)$ \\
\hline Democrat (vs. Repub) & & .16 & (.14) & .01 & (.14) & & .17 & $(.13)$ & .18 & (.13) & & .10 & $(.13)$ & .07 & $(.14)$ \\
\hline Independent (vs. Repub) & & .28 & $(.22)$ & .31 & $(.22)$ & & .38 & $(.22)$ & .25 & $(.21)$ & & .59 & $(.23)$ & .53 & $(.24)$ \\
\hline Other Party (vs. Repub) & & .25 & (.14) & .23 & $(.15)$ & & .30 & $(.15)$ & .33 & $(.15)$ & & .30 & $(.15)$ & .37 & $(.15)$ \\
\hline Liberal $=>$ Conservative & & .05 & $(.06)$ & .11 & $(.07)$ & & .08 & $(.05)$ & .14 & $(.06)$ & & -.02 & $(.05)$ & .00 & $(.06)$ \\
\hline Hierarch & & & & .20 & $(.37)$ & & & & .03 & $(.36)$ & & & & .25 & $(.38)$ \\
\hline Individ & & & & -.17 & $(.36)$ & & & & -.15 & $(.35)$ & & & & -.02 & $(.37)$ \\
\hline Hierarch $\mathrm{x}$ Individ & & & & .16 & $(.07)$ & & & & .07 & $(.07)$ & & & & .14 & $(.07)$ \\
\hline Hierarch x Risk & & & & -.47 & $(.54)$ & & & & .00 & $(.53)$ & & & & -.92 & $(.52)$ \\
\hline Individ x Risk & & & & .24 & $(.53)$ & & & & .61 & $(.52)$ & & & & -.54 & $(.51)$ \\
\hline Hierarch x Individ x Risk & & & & -.32 & $(.10)$ & & & & -.20 & $(.10)$ & & & & -.16 & $(.10)$ \\
\hline $\operatorname{LR} \chi_{2}$ & 11.20 & 29.74 & & 618.72 & & 18.50 & 31.60 & & 172.69 & & 25.84 & 46.33 & & 499.60 & \\
\hline G-test (delta LR $\chi 2$ ) & & 18.54 & & 588.98 & & & 13.10 & & 141.09 & & & 2.49 & & 453.27 & \\
\hline
\end{tabular}

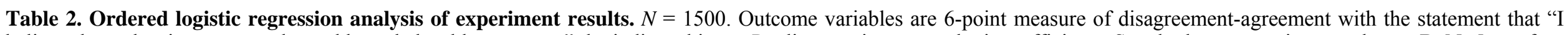

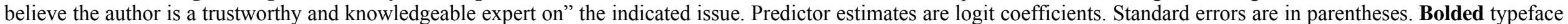
indicates predictor coefficient, model $\chi 2$, or $G$-statistic (incremental change in model $\chi 2$ associated with additional predictors) is statistically significant at $p<0.05$. 
For two of the three risks (global warming, and concealed carry), the impact of the experimental manipulation was largest for hierarchical individualists (for nuclear waste disposal it was the same for both groups). Nevertheless, consistent with the hypotheses, the position attributed to the authors also had substantial effects on egalitarian communitarians, whose likelihood of agreement in the "low risk" condition was always lower than it was in the "high risk" condition.

\subsubsection{Multivariate Analyses}

Table 2 presents a set of ordered logistic regression analyses performed to enable a more exacting test of the experiment hypotheses. Assessment of expertise for each fictional author was regressed against predictors in three steps. The first consisted simply of a dummy variable (Risk), coded 0 for "low risk" and 1 for "high risk." The results thus reflect the main effect of the experimental manipulation. As reflected in the response frequencies, being assigned to the "high risk" treatment predicted a significant increase in the likelihood of agreeing that the author who addressed nuclear waste disposal was an expert, whereas being assigned to the "high risk" treatment predicted a decrease in the likelihood of agreeing the authors who addressed climate change and gun control were experts.

In the second and third steps, the control variables and the cultural worldview variables were entered into the analyses. In addition to the product interaction term for Hierarchy and Individualism (Hierarch $\mathrm{x}$ Individ), the third step contains product interaction terms for each culture variable and the experimental treatment variable (Hierarch $\mathrm{x}$ Risk and Individ x Risk) and a three-way product interaction term for the cultural variables together and the experimental treatment variable (Hierarch $\mathrm{x}$ Indvid x Risk); these terms measure individual differences in the response to the experimental manipulation associated with subjects' cultural worldviews. Again, the cultural variables (and the associated interaction terms) were entered in as a block because the study hypotheses contemplated effects from the sum and interaction of Hierarchy and Individualism. ${ }^{4}$ The significant $G$-statistic associated with the third step in each

\footnotetext{
${ }^{4}$ In the full specified models, the coefficient for Risk was positive and significant for all three authors. However, because the coefficient for Risk in those models indicates the effect of assigning the author the "high risk" position
} 
model indicates that addition of the cultural variables explains additional variance in subjects responses. In addition, the negative sign of the coefficients for the 3-way interaction terms indicate that the more hierarchical and individualistic the subject is, the more the likelihood decreases that she will agree that the authors are experts when they are depicted as reaching the "high risk" conclusion. Again, however, the most straightforward and informative way to assess the sign, the size, and the significance (statistical and practical) of effect of the culture variables is through statistical simulation.

Simulation results are reported in Figure 8. They reflect how much more likely, all else equal, a subject with one combination of values is than the other to agree that the indicated author is a "trustworthy and knowledgeable expert" (determined by simulating responses when the relevant cultural worldview predictors are set one standard deviation from the mean in the indicated directions; the experimental condition variable at either low or high risk; the product interaction terms to the appropriate corresponding values; and all other predictors in the regression model to their means (Gellman \& Hill, pp. 178-81, 2007)).

The results are consistent with the study hypotheses. When the author is assigned a "high risk" position, being simultaneously egalitarian and communitarian predicts a substantially greater likelihood the author will be perceived as an expert than does being simultaneously hierarchical and individualistic (other influences held constant); similarly, when the author is assigned a "low risk" prediction, being simultaneously hierarchical and individualist predicts a substantially greater likelihood the author will be perceived as an expert than does being simultaneously egalitarian and communitarian. Once more, the effects are most dramatic for the climate change and gun control authors, but remains significantstatistically and practically_-for the nuclear-waste-disposal author: whereas being simultaneously hierarchical and individualistic as opposed to simultaneously egalitarian and communitarian predicts a 31.2 $( \pm 8.7)$ percentage-point greater likelihood of perceiving the author to be an expert in the "low risk" condition, it predicts a $21.5( \pm 9.3)$ percentage-point lower likelihood of such a perception in the "high risk"

when Hierarchy and Individualism have values of 0 - a score outside the range of the scale - the coefficient does not 
condition - or a 50 percentage-point shift in the difference in likelihoods overall as a result of the experimental manipulation.

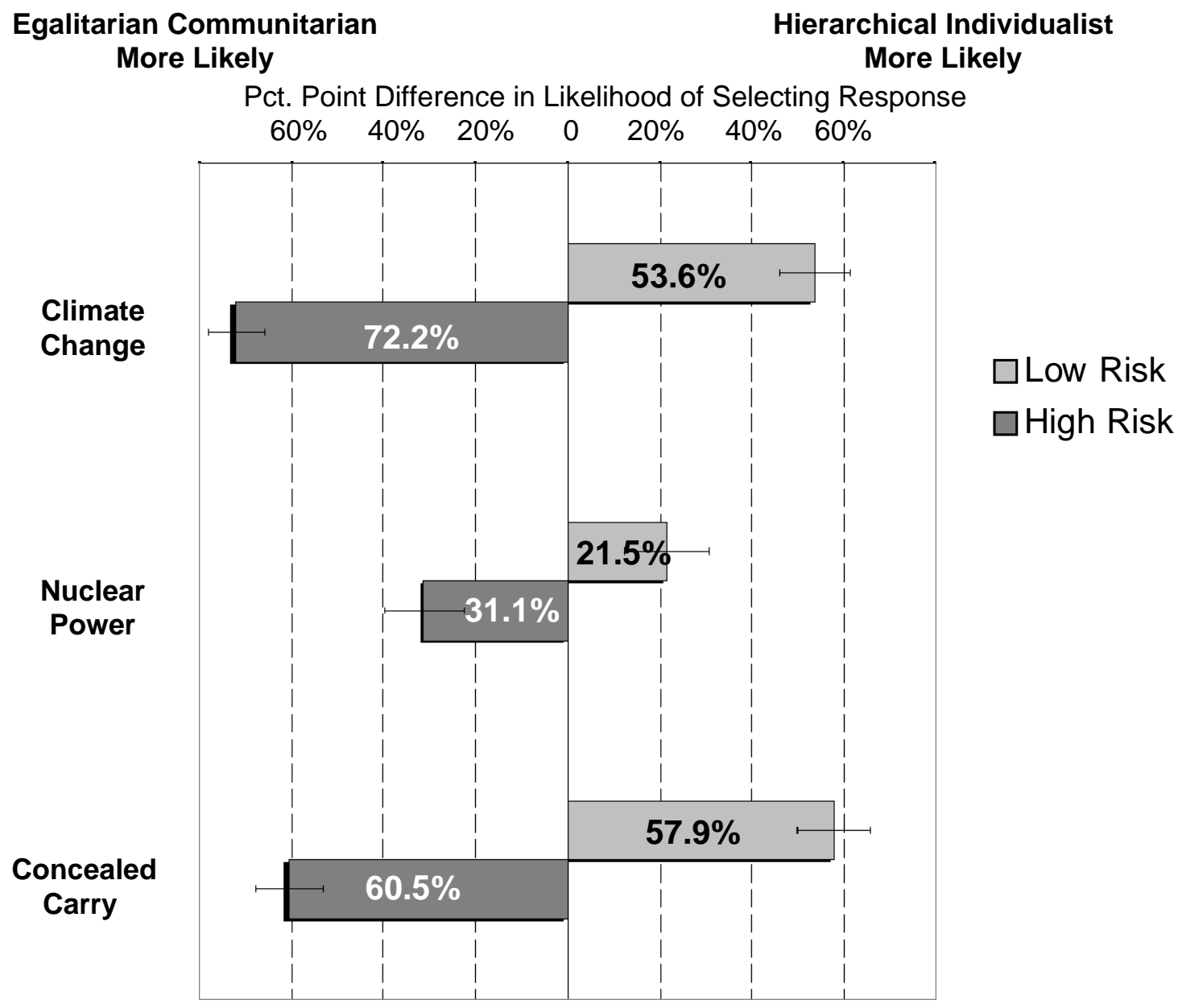

Figure 8. Impact of authors' positions on the perception of his expertise by subjects of diverse cultural predispositions. $N=1,500$. Derived from ordered logistic regression analysis (Table 2). Bars indicate how much more likely a subject with the indicated worldview is to agree than is a subject with the opposing worldview that the author is a "knowledgeable and trustworthy expert" when that author is assigned a particular position ("high" or "low risk"). Cultural worldview values have been set one standard deviation from the mean in the indicated directions on the "hierarchy-egalitarian" and "individualist-communitarian" worldview scales. Confidence intervals reflect .95 level of confidence.

admit of meaningful interpretation on its own (Aiken, West \& Reno, p. 38, 1991). 


\section{Discussion and Conclusions}

\subsection{Summary of Findings}

The goal of the study was to examine a distinctive explanation for the failure of members of the public to form beliefs consistent with apparent scientific consensus on climate change and other issues of risk. We hypothesized that scientific opinion fails to quiet societal dispute on such issues not because members of the public are unwilling to defer to experts but because culturally diverse persons tend to form opposing perceptions of what experts believe. Individuals systematically overestimate the degree of scientific support for positions they are culturally predisposed to accept as a result of a cultural availability effect that influences how readily they can recall instances of expert endorsement of those positions.

The study furnished two forms of evidence in support of this basic hypothesis. The first was the existence of a strong correlation between individuals' cultural values and their perceptions of scientific consensus on risks known to divide persons of opposing worldviews. Subjects holding hierarchical and individualistic outlooks, on the one hand, and ones holding egalitarian and communitarian outlooks, on the other, significantly disagreed about the state of expert opinion on climate change, nuclear waste disposal, and handgun regulation. It is possible, of course, that one or the other of these groups is better at discerning scientific consensus than the other. But because the impressions of both groups converged and diverged from positions endorsed in NAS "expert consensus" reports in a pattern reflective of their respective predispositions, it seems more likely that both hierarchical individualists and egalitarian communitarians are fitting their perceptions of scientific consensus to their values.

The second finding identified a mechanism that could explain this effect. When asked to evaluate whether an individual of elite academic credentials, including membership in the NAS, was a "knowledgeable and trustworthy expert," subjects' answers proved conditional on the fit between the position the putative expert was depicted as adopting (on climate change, on nuclear waste disposal, or on handgun regulation) and the position associated with the subjects' cultural outlooks.

The size of the effects was not uniform across the types of risks examined. The largest disparity occurred in connection with global warming; differences in perceptions of consensus, and in the impact of authors' positions in the experiment, were smallest for nuclear power, and of intermediate size for con- 
cealed carry laws. The study furnishes no particular insight into the source of these differences. We speculate that they reflect the relative contemporary centrality of these issues as sources of political conflict, and the absence of nuclear power construction in the United States over the last two decades in particular.

Even in the case of nuclear power, however, the differences in the magnitude of the observed effect were statistically significant and large enough in magnitude, we submit, to be of practical importance. For example, multivariate analysis of the experiment results revealed that (all else equal) the gap between the predicted likelihood that a modestly hierarchical, individualistic subject would see the author as an expert, on the one hand, and the likelihood that a modestly one would, on the other, shifted by over 50percentage points when the author's position was manipulated from "high risk" to "low."

A disparity of this magnitude in how much more likely one is to count some as "experts" those who endorse rather than opposes one's cultural predisposition would over time naturally lead to a culturally skewed impression of what most experts believe. Even when experts by and large agree, individuals of diverse worldviews can be expected under such conditions to end up with substantially different assessments of the state of scientific consensus.

\subsection{Understanding the Cultural Cognition of Risk}

Adding this dynamic to the set of mechanisms through which cultural cognition shapes perceptions of risk and related facts, it is possible to envision a more complete picture of how these processes work in concert. On this view, cultural cognition can be seen as injecting a biasing form of endogeneity into a process roughly akin to Bayesian updating.

Even as an idealized normative model of rational decisionmaking, Bayesian information processing is necessarily incomplete. Bayesianism furnishes an algorithm for rationally updating one's beliefs in light of new evidence: one's estimate of the likelihood of some proposition should be revised in proportion to the probative weight of any new evidence (by multiplying one's "prior odds" by a "likelihood ratio" that represents how much more consistent new evidence is with that proposition than with its negation) (Raiffa 1968). This instruction, however, merely tells a person how a prior estimate and new evidence of a particular degree of probity should be combined to produce a revised estimate; it has noth- 
ing to say about what her prior estimate should be or, even more importantly, how she should determine the probative force (if any) of a putatively new piece of evidence.

Consistently with Bayesianism, an individual can use pretty much any process she wantsincluding some prior application of the Bayesian algorithm itself - to determine the probity of new evidence (Raiffa 1968), but any process that gauges the weight (or likelihood ratio) of the new evidence based on its consistency with the individual's prior estimate of the proposition in question will run into an obvious difficulty. In the extreme, an individual might adopt the rule that she will assign no probative weight to any asserted piece of evidence that contradicts her prior belief. If she does that, she will of course never change her mind and hence never revise a mistaken belief, since she will necessarily dismiss all contrary evidence, no matter how well founded, as lacking credibility. In a less extreme variant, an individual might decide merely to assign new information that contradicts her prior belief less probative weight than she otherwise would have; in that case, a person who starts with a mistaken belief might eventually correct it, but only after being furnished with more evidence than would have been necessary if she had not discounted any particular item of contrary evidence based on her mistaken starting point. A person who employs Bayesian updating is more likely to correct a mistaken belief, and to do so sooner, if she has a reliable basis exogenous to her prior belief for identifying the probative force of evidence that contravenes that belief (Rabin \& Schrag 1999).

When mechanisms of cultural cognition figure in her reasoning, a person processes information in a manner that is equivalent to one who is assigning new information probative weigh based on its consistency with her prior estimation (Figure 9). Because of identity protective cognition (Sherman \& Cohen 2006; Kahan, Braman, Gastil, Slovic \& Mertz 2007) and affect (Peters, Burraston \& Mertz 2004), such a person is highly likely to start with a risk perception that is associated with her cultural values. She might resolve to evaluate the strength of contrary evidence without reference to her prior beliefs. However, because of culturally biased information search and culturally biased assimilation (Kahan, Braman, Gastil, Cohen \& Slovic 2009), she is likely to attend to the information in a way that reinforces her prior beliefs and affective orientation (Jenkins-Smith 2001). 

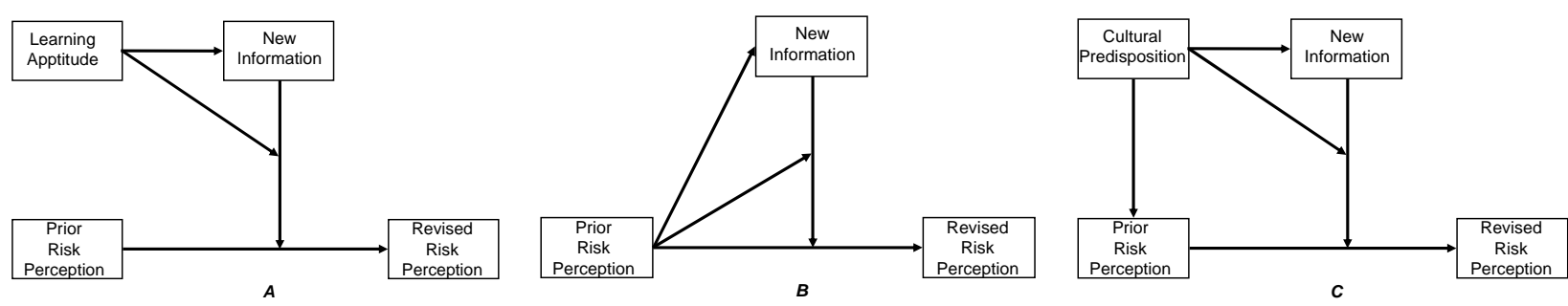

Figure 9. Risk perception updating and the effect of cultural cognition. How readily individuals will revise their perceptions of risk depends on their "learning aptitude" - that is, their motivation and capacity to seek out new information, to recognize it as such, and to give it appropriate effect $(A)$. If their learning aptitude is guided by their existing perceptions - that is, if they are motivated to seek out new information that affirms their prior risk perceptions, and selectively to recognize and give effect to new information in a manner that reinforces their priorsindividuals will exhibit closed-mindedness (B) (Rabin \& Schrag 1999). Individuals are vulnerable to this form of closed-mindedness as a result of cultural cognition insofar as the same cultural predispositions that shape their prior risk perceptions also motivate their search for new information and their recognition and assimilation of it $(C)$.

Perhaps mindful of the limits of her ability to gather and interpret evidence on her own, such an individual might choose to defer or to give considerable weight to the views of experts. But through the cultural availability effect examined in our study, she is likely to overestimate the proportion of experts who hold the view consistent with her own predispositions. Like the closed-minded Bayesian whose assessment of the probative value of new information is endogenous to his prior beliefs, then, such an individual will either not change her mind or will change it much more slowly than she should, because the same predisposition that informs her priors will also be unconsciously shaping her ability to recognize and assign weight to all manner of evidence, including the opinion of scientists (Zimper \& Ludwig 2009).

\subsection{Improving Risk Communication}

This conclusion does not imply, however, that there is no prospect for rational public deliberations informed by the best scientific evidence on global warming, nuclear waste disposal, handguns, and like issues. But because the source of the enfeebled power of scientific opinion is different from what is normally thought, the treatment must be something other than what is normally prescribed. It is not enough to assure that scientifically sound information-including evidence of what scientists themselves believe - is widely disseminated: cultural cognition strongly motivates individuals — of all worldviews- 
to recognize such information as sound in a selective pattern that reinforces their cultural predispositions. To overcome this effect, communicators must attend to the cultural meaning as well as the scientific content of information.

Research informed by cultural cognition and related theories is making progress in identifying communication strategies that possess this quality. One is identity affirmation. When shown risk information (e.g., global temperatures are increasing) that they associate with a conclusion threatening to their cultural values (commerce must be constrained), individuals tend to react dismissively toward that information; however, when shown that the information in fact supports or is consistent with a conclusion that affirms their cultural values (society should rely more on nuclear power), such individuals are more likely to consider the information open-mindedly (Kahan 2010; Cohen, Bastardi, Sherman, Hsu, McGoey, 2007; Cohen, Aronson \& Steele, 2000).

Another is pluralistic advocacy. Individuals reflexively reject information inconsistent with their predispositions when they perceive that it is being advocated by experts whose values they reject and opposed by ones whose values they share. In contrast, they attend more open-mindedly to such information, and are much more likely to accept it, if they perceive that there are experts of diverse values on both sides of the debate (Earle \& Cvetkovich 1995; Kahan et al. in press).

Finally, there is narrative framing. Individuals tend to assimilate information by fitting it to preexisting narrative templates or schemes that invest the information with meaning. The elements of these narrative templates - the identity of the stock heroes and villains, the nature of their dramatic struggles, and the moral stakes of their engagement with one another-vary in identifiable and recurring ways across cultural groups. By crafting messages to evoke narrative templates that are culturally congenial to target audiences, risk communicators can help to assure that the content of the information they are imparting receives considered attention across diverse cultural groups (Earle \& Cvetckovich 1995; Jones \& McBeth 2010).

Research on these and related strategies for dispelling the tendency of cultural cognition to generate conflict in public deliberations about risk are at an early stage. Further development of this aspect of science communication, we believe, is critical to enlightened democratic policymaking. 
$-32-$ 
Adams, J. (1995). Risk. London [England] Bristol, PA: UCL Press.

Aiken, L. S., West, S. G., \& Reno, R. R. (1991). Multiple Regression: Testing and Interpreting Interactions. Newbury Park, Calif.: Sage Publications.

Barke, R. P., \& Jenkins-Smith, H. C. (1993). Politics and Scientific Expertise: Scientists, Risk Perception, and Nuclear Waste Policy. Risk Analysis, 13(4), 425-439.

Boholm, Ã. s. (2003). The cultural nature of risk: Can there be an anthropology of uncertainty? Ethnos, 68(2), 159 - 178.

Cohen, G. L., Aronson, J., \& Steele, C. M. (2000). When Beliefs Yield to Evidence: Reducing Biased Evaluation by Affirming the Self. Personality and Social Psychology Bulletin, 26(9), 1151-1164.

Cohen, G. L. (2003). Party over Policy: The Dominating Impact of Group Influence on Political Beliefs. J. Personality \& Soc. Psych., 85(5), 808-822.

Cohen, G. L., Bastardi, A., Sherman, D. K., Hsu, L., McGoey, M., \& Ross, L. (2007). Bridging the partisan divide: Self-affirmation reduces ideological closed-mindedness and inflexibility in negotiation. Journal of Personality and Social Psychology, 93(3), 415-430.

Cohen, J. (1988). Statistical Power Analysis for the Behavioral Sciences. Hillsdale, NJ: Lawrence Earlbaum Assocs.

Cohen, J., Cohen, P., West, S. G., \& Aiken, L. S. (2003). Applied Multiple Regression/Correlation Analysis for the Behavioral Sciences (3rd ed.). Mahwah, N.J.: L. Erlbaum Associates.

Dake, K. (1991). Orienting Dispositions in the Perception of Risk: An analysis of contemporary worldviews and cultural biases. J. Cross-Cultural Psych., 22, 61-82.

DiMaggio, P. (1997). Culture and cognition. Annual Review of Sociology, 23, 263-287.

Douglas, M. (1986). How Institutions Think (1st ed.). Syracuse, N.Y.: Syracuse University Press.

Douglas, M., \& Wildavsky, A. B. (1982). Risk and Culture: An Essay on the Selection of Technical and Environmental Dangers. Berkeley: University of California Press.

Earle, T. C., \& Cvetkovich, G. (1995). Social trust: toward a cosmopolitan society. Westport, Conn.: Praeger.

Finucane, M. L., Alhakami, A., Slovic, P., \& Johnson, S. M. (2000). The Affect Heuristic in Judgments of Risks and Benefits. Journal of Behavioral Decision Making, 13(1), 1-17.

Gellman, A., \& Hill, J. (2007). Data Analysis Using Regression and Multilevel/Hierarchical Models. Cambridge ; New York: Cambridge University Press. 
Irwin, A., \& Wynne, B. (1996). Misunderstanding science? The public reconstruction of science and technology. Cambridge ; New York: Cambridge University Press.

Jaccard, J., \& Turrisi, R. (2003). Interaction Effects in Multiple Regression (2nd ed.). Thousand Oaks, Calif.: Sage Publications.

Jenkins-Smith, H. (2001). Modeling Stigma: An Empirical Analysis of Nuclear Waste Images of Nevada. In J. Flynn, P. Slovic \& H. Kunreuther (Eds.), Risk, media, and stigma: understanding public challenges to modern science and technology (pp. 107-132). London ; Sterling, VA: Earthscan.

Jones, M., \& McBeth, M. (2010). A Narrative Policy Framework: Clear Enough to Be Wrong?, Policy Studies J. 38, 329-53.

Judd, C. M. (2000). Everyday Data Analysis in Social Psychology: Comparisons of Linear Models. In H. T. Reis \& C. M. Judd (Eds.), Handbook of research methods in social and personality psychology (pp. 370-392). New York: Cambridge University Press.

Kahan, D. (in press). Cultural Cognition as a Conception of the Cultural Theory of Risk. In Handbook of Risk Theory, Sabine Roeser (Ed.).

Kahan, D. (2010). Fixing the Communications Failure. Nature, 463, 296-297.

Kahan, D. M., \& Braman, D. (2003). More Statistics, Less Persuasion: A Cultural Theory of Gun-Risk Perceptions. U. Pa. L. Rev., 151, 1291-1327.

Kahan, D. M., Braman, D., Cohen, G. L., Gastil, J., \& Slovic, P. (in press). Who Fears the HPV Vaccine, Who Doesn't, and Why? An Experimental Study of the Mechanisms of Cultural Cognition. L. \& Human Behavior. Advance publication available at http://dx.doi.org/10.1007/s10979-009-9201-0.

Kahan, D. M., Braman, D., Gastil, J., Slovic, P., \& Mertz, C. K. (2007). Culture and IdentityProtective Cognition: Explaining the White-Male Effect in Risk Perception. Journal of Empirical Legal Studies, 4(3), 465-505.

Kahan, D. M., Braman, D., Monahan, J., Callahan, L., \& Peters, E. (2010). Cultural Cognition and Public Policy: The Case of Outpatient Commitment Laws. L. \& Human Behavior, $\underline{34,118-140 .}$.

Kahan, D. M., Braman, D., Slovic, P., Gastil, J., \& Cohen, G. (2009). Cultural Cognition of the Risks and Benefits of Nanotechnology. Nature Nanotechnology, 4(2), 87-91.

Kahan, D. M., Slovic, P., Braman, D., \& Gastil, J. (2006). Fear of Democracy: A Cultural Critique of Sunstein on Risk. Harvard Law Review, 119, 1071-1109.

Kahneman, D., \& Tversky, A. (1982). Availability: A Heuristic for Judging Frequency and Probability. In D. Kahneman, P. Slovic \& A. Tversky (Eds.), Judgment Under Uncertainty: Heuristics and Biases (pp. 163-178). Cambridge ; New York: Cambridge University Press. 
King, G., Honaker, J., Joseph, A., \& Scheve, K. (2001). Analyzing Incomplete Political Science Data: An Alternative Algorithm for Multiple Imputation. Am. Pol. Sci. Rev., 95(1), 49-69.

King, G., Tomz, M., \& Wittenberg., J. (2000). Making the Most of Statistical Analyses: Improving Interpretation and Presentation. Am. J. Pol. Sci., 44(2), 347-361.

Lord, C. G., Ross, L., \& Lepper, M. R. (1979). Biased Assimilation and Attitude Polarization Effects of Prior Theories on Subsequently Considered Evidence. Journal of Personality and Social Psychology, 37(11), 2098-2109.

Mamadouh, V. (1999). Grid-Group Cultural theory: An Introduction. GeoJournal, 47, 395-409.

Marris, C., Langford, I. H., \& O'Riordan, T. (1998). A Quantitative Test of the Cultural Theory of Risk Perceptions: Comparison with the Psychometric Paradigm. Risk Analysis, 18(5), 635-647.

National Research Council. Committee to Improve Research Information and Data on Firearms., Wellford, C. F., Pepper, J., Petrie, C., \& National Research Council (U.S.). Committee on Law and Justice. (2004). Firearms and violence : a critical review. Washington, DC: National Academies Press.

National Research Council Committee on Analysis of Global Change Assessments. (2007). Analysis of global change assessments: lessons learned Washington, D.C.: National Academies Press.

National Research Council. Board on Radioactive Waste Management. (1990). Rethinking highlevel radioactive waste disposal: A position statement of the Board on Radioactive Waste Management, Commission on Geosciences, Environment, and Resources, National Research Council. Washington, D.C.: National Academy Press.

Newport, F. (2008, April 21, 2008). Little Increase in Americans' Global Warming Worries. Gallup Polls, from http://www.gallup.com/poll/106660/Little-Increase-AmericansGlobal-Warming-Worries.aspx.

Peters, E. M., Burraston, B., \& Mertz, C. K. (2004). An Emotion-Based Model of Risk Perception and Stigma Susceptibility: Cognitive Appraisals of Emotion, Affective Reactivity, Worldviews, and Risk Perceptions in the Generation of Technological Stigma. Risk Analysis, 24(5), 1349-1367.

Pew Research Center. (2009, Oct. 22, 2009). Fewer Americans See Solid Evidence of Global Warming, from http://people-press.org/reports/pdf/556.pdf.

Rabin, M., \& Schrag, J. L. (1999). First Impressions Matter: A Model of Confirmatory Bias. The Quarterly Journal of Economics, 114(1), 37-82.

Raiffa, H. (1968). Decision Analysis. Reading, Mass.,: Addison-Wesley.

Rayner, S. (1992). Cultural Theory and Risk Analysis. In S. Krimsky \& D. Golding (Eds.), Social Theories of Risk (pp. pp. 83-115). Westport, Conn.: Praeger. 
Rubin, D. B. (2004). Multiple imputation for nonresponse in surveys. Hoboken, N.J. ;: WileyInterscience.

Schulz-Hardt, S., Frey, D., Luthgens, C., \& Moscovici, S. (2000). Biased information search in group decision making. Journal of Personality and Social Psychology, 78(4), 655-669.

Sherman, D. K., \& Cohen, G. L. (2006). The psychology of self-defense: Self-affirmation theory. In M. P. Zanna (Ed.), Advances in Experimental Social Psychology (Vol. 38, pp. 183242).

Siegrist, M., Cvetkovich, G., \& Roth, C. (2000). Salient Value Similarity, Social Trust, and Risk/Benefit Perception. Risk Analysis, 20(3), 353-362.

Sjöberg, L. (1997). Explaining risk perception: an empirical evaluation of cultural theory. Risk Decision and Policy, 2(2), 113-130.

Sjöberg, L. (1998). World Views, Political Attitudes, and Risk Perception. Risk: Health, Safety and Environment, 9, 137-152.

Slovic, P. (2000). The Perception of Risk. London ; Sterling, VA: Earthscan Publications.

Slovic, P., Flynn, J. H., \& Layman, M. (1991). Perceived Risk, Trust, and the Politics of Nuclear Waste. Science, 254(5038), 1603-1607.

Streiner, D. L. (2003). Unicorns Do Exist: A Tutorial on "Proving" the Null Hypothesis. Canadian Journal of Psychiatry, 48, 756-761.

Sunstein, C. R. (2005). Laws of Fear: Beyond the Precautionary Principle. Cambridge, UK ; New York: Cambridge University Press.

Thompson, M., Ellis, R., \& Wildavsky, A. (1990). Cultural Theory. Boulder Colo.: Westview Press.

Wildavsky, A., \& Dake, K. (1990). Theories of risk perception: Who fears what and why? Daedalus, 114, 41-60.

Zimper, A., \& Ludwig, A. (2009). On attitude polarization under Bayesian learning with nonadditive beliefs. Journal of Risk and Uncertainty, 39(2), 181-212. 


\section{Appendix. Select Measures from Study Instrument}

\section{Cultural Worldview Measures (Rotated)}

People in our society often disagree about how far to let individuals go in making decisions for themselves. How strongly you agree or disagree with each of these statements? [strongly disagree, moderately disagree, slightly disagree, slightly agree, moderately agree, strongly agree; items prefixed by "C" or "E" were reverse coded]

IINTRSTS. The government interferes far too much in our everyday lives.

CHARM. Sometimes government needs to make laws that keep people from hurting themselves.

IPROTECT. It's not the government's business to try to protect people from themselves.

IPRIVACY. The government should stop telling people how to live their lives.

CPROTECT. The government should do more to advance society's goals, even if that means limiting the freedom and choices of individuals.

CLIMCHOI. Government should put limits on the choices individuals can make so they don't get in the way of what's good for society.

People in our society often disagree about issues of equality and discrimination. How strongly you agree or disagree with each of these statements? [strongly disagree, moderately disagree, slightly disagree, slightly agree, moderately agree, strongly agree]

HEQUAL. We have gone too far in pushing equal rights in this country.

EWEALTH. Our society would be better off if the distribution of wealth was more equal.

ERADEQ. We need to dramatically reduce inequalities between the rich and the poor, whites and people of color, and men and women.

EDISCRIM. Discrimination against minorities is still a very serious problem in our society.

HREVDIS2. It seems like blacks, women, homosexuals and other groups don't want equal rights, they want special rights just for them.

HFEMININ. Society as a whole has become too soft and feminine.

\section{Perceptions of Scientific Opinion (items rotated)}


We'd now like to know what you think expert scientists believe about these issues. We'll ask you to read a series of statements. For each, please indicate whether you think most expert scientists agree with the statement, most expert scientists disagree with the statement, or expert scientists are divided in their views.

GWREAL. Global temperatures are increasing.

GWHUMAN. Human activity is causing global warming.

NUKE Radioactive wastes from nuclear power can be safely disposed of in deep underground storage facilities.

GUN. Permitting adults without criminal records or histories of mental illness to carry concealed handguns in public decreases violent crime.

\section{Perceptions of Scientific Expertise (authors rotated)}

Imagine that a close friend told you he or she was undecided on the issue of ["global warming," "the disposal of nuclear waste," or "the issue of gun control"]. and would like to get more information. [In the case of gun control: 'Of particular concern to your friend is the issue of 'concealed carry laws,' which permit adults without criminal records or histories of mental illness to possess concealed handguns in public."] The friend tells you that he or she is planning to read a book about the issue but before taking the time to do so would like to get your opinion on whether the author seems like a knowledgeable and trustworthy expert.

Below is a book excerpt and some information about the book's author. How strongly would you agree or disagree with this statement [Strongly disagree, moderately disagree, slightly disagree, slightly agree, moderately agree, strongly agree]:

"I believe the author is a trustworthy and knowledgeable expert on [global warming, gun control, or nuclear power]." 